\title{
Comparison between the Large-Scale Environments of Moderate and Intense Precipitating Systems in the Mediterranean Region
}

\author{
BeAtriz M. Funatsu And Chantal Claud \\ Laboratoire de Météorologie Dynamique, CNRS/IPSL, Palaiseau, France \\ JEAN-PiERRE ChABOUREAU \\ Laboratoire d'Aerologie, University of Toulouse/CNRS, Toulouse, France
}

\begin{abstract}
A characterization of the large-scale environment associated with precipitating systems in the Mediterranean region, based mainly on NOAA-16 Advanced Microwave Sounding Unit (AMSU) observations from 2001 to 2007, is presented. Channels 5, 7, and 8 of AMSU-A are used to identify upper-level features, while a simple and tractable method, based on combinations of channels 3-5 of AMSU-B and insensitive to land-sea contrast, was used to identify precipitation. Rain occurrence is widespread over the Mediterranean in wintertime while reduced or short lived in the eastern part of the basin in summer. The location of convective precipitation shifts from mostly over land from April to August, to mostly over the sea from September to December. A composite analysis depicting large-scale conditions, for cases of either rain alone or extensive areas of deep convection, is performed for selected locations where the occurrence of intense rainfall was found to be important. In both cases, an upper-level trough is seen to the west of the target area, but for extreme rainfall the trough is narrower and has larger amplitude in all seasons. In general, these troughs are also deeper for extreme rainfall. Based on the European Centre for Medium-Range Weather Forecasts operational analyses, it was found that sea surface temperature anomalies composites for extreme rainfall are often about $1 \mathrm{~K}$ warmer, compared to nonconvective precipitation conditions, in the vicinity of the affected area, and the wind speed at $850 \mathrm{hPa}$ is also stronger and usually coming from the sea.
\end{abstract}

\section{Introduction}

The Mediterranean region is a densely populated area under climatic and environmental stresses, particularly concerning the availability of water resources, and is one of the most responsive regions to climate change (e.g., Hulme et al. 1999; Giorgi 2006). While the water availability is of great importance, severe weather events causing heavy rainfall and floods also add to the socioeconomic distress. The Mediterranean Experiment (MedEx) database presents several cases of severe weather (including strong winds, storms and floods) throughout the Mediterranean region, many of which caused millions of euros in damages. In fact, trend analysis of daily rainfall data for the period of 1951-95

Corresponding author address: Beatriz M. Funatsu, Laboratoire de Météorologie Dynamique, Ecole Polytechnique, 91128 Palaiseau CEDEX, France.

E-mail: funatsu@lmd.polytechnique.fr based on 265 Mediterranean stations have shown that the central-western Mediterranean faced a change in the rainfall distribution with a reduction of mean precipitation totals but an increase in the occurrence of heavy precipitating events (Alpert et al. 2002).

Several factors play a role in the development and occurrence of heavy rainfall in the Mediterranean, for example, cyclones and cyclogenesis (Jansà et al. 2001; Kahana et al. 2002; Zangvil et al. 2003; Tsvieli and Zangvil 2007), upper-level troughs (Massacand et al. 1998; Fourrié et al. 2003; Chaboureau and Claud 2006; Kotroni et al. 2006), and mesoscale convective systems (Riosalido 1990; Delrieu et al. 2005). In many instances these factors act in synergy, bringing together all the elements favorable to strong rainfall. For example, Nuissier et al. (2008) and Ducrocq et al. (2008) have shown that a combination of orographic forcing, low-level moisture convergence, strong evaporation and a stationary convective system have all contributed to the intensity of three heavy precipitation events in south of France. In the Alpine region, narrow, 
north-south-oriented upper-level troughs often act to impinge moisture-loaded air into its relieves, promoting the release of conditional instability and producing heavy precipitating events that lead to severe floods (e.g., Massacand et al. 1998; Fehlmann et al. 2000; Hoinka et al. 2006; Martius et al. 2006).

Despite our knowledge of the necessary key ingredients for a strong rainfall, its predictability is limited at best to a couple of days because there is a large range of processes that play a role, as well as uncertainties of the system due to the inherent nonlinearity of the atmospheric dynamics and the several scale interactions. In this sense, there has been an increased interest in identifying and quantifying the sources of uncertainties that affect the forecast and climate projection in the Mediterranean region. It is thus important to have a description as precise as possible of the environment in which such high-impact weather systems develop. This work aims at contributing to this effort, more specifically, to contrast the large-scale environment of systems yielding moderate or very intense precipitation. To this end, we use the data provided by the Advanced Microwave Sounding Unit (AMSU) radiometer to detect moderate and heavy precipitating areas and their embedded upper-level environment. AMSU observations allows a screening of precipitation over the whole of the Mediterranean basin, including the sea, where in situ observations are scarce, providing a complementary picture from studies based on reanalysis and ground station data. In addition, operational analyses data of sea surface temperature (SST) and near-surface winds from the European Centre for Medium-Range Weather Forecasts (ECMWF) are used to describe near-surface large-scale conditions. This study complements that of Funatsu et al. (2008), which addressed the relationship between upperlevel troughs and associated precipitation in the Mediterranean region using AMSU. They found that when an upper-level trough is present there is moderate precipitation in its vicinity in at least $60 \%$ of the cases, with little interseasonal variation, while the frequency of convective rain presents a pronounced regional and seasonal dependency. Here we address the issue from the opposite point of view (i.e., we base our analysis on events of precipitation and examine what are the large-scale conditions in which they are embedded). We then compare the results obtained here with other "regional" climatologies (e.g., Alpine region, south of France, Israel), and also examine conditions for less studied regions in the Mediterranean (e.g., North Africa).

A description of the AMSU data is provided in section 2, as well as the methodology for detection of rain and upper-level systems. Section 3 presents the spatial and seasonal distribution of precipitation for the Mediter- ranean basin as a whole, including a verification of results against alternative climatologies. The contrast between the large-scale circulation for precipitating systems with or without convective nature in specific regions that are frequently affected by heavy rainfall is presented in section 4 . The final Section contains a summary and discussion including a comparison of our results with those of other authors, in relation to large-scale circulation patterns and weather regimes.

\section{Data and method}

AMSU is a cross-scanning microwave instrument flying on board the National Oceanic and Atmospheric Administration (NOAA) polar-orbiting satellites starting in 1998. It consists of two modules: AMSU-A, which has channels in the molecular oxygen frequencies (50-58 $\mathrm{GHz}$ ), mainly designed for atmospheric temperature profile retrieval, and AMSU-B, which has three channels centered at $183 \mathrm{GHz}$ (water vapor absorption line), designed for optimal moisture retrieval. Furthermore, both modules have window channels, which are not used in this study. The near-nadir instantaneous field of view of AMSU-A and -B is of 48 and $16 \mathrm{~km}$, respectively; both have a swath width of approximately $2300 \mathrm{~km}$.

In the present study we use only NOAA-16 (launched on 21 September 2000) AMSU-A and -B for the period of January 2001 to December 2007 in order to avoid intersatellite biases. NOAA-16 AMSU-B has small scan asymmetries, comparable to the instrument noise (Buehler et al. 2005) while AMSU-A data presents scan asymmetries, but the effect is mostly significant in the window channels $(23.8,31.4,50.3$, and $89 \mathrm{GHz})$; for the remaining AMSU-A channels this effect is attenuated by the presence of the atmosphere (Weng et al. 2003). (Further details on the instrument can be found in the NOAA's KLM User's Guide available online at http:// www2.ncdc.noaa.gov/docs/klm/.)

AMSU-A data were corrected for limb effect using coefficients derived from the Radiative Transfer for Television and Infrared Observation Satellite (TIROS) Operational Vertical Sounder (RTTOV). Details on the correction procedure can be found in Funatsu et al. (2007b). After the limb correction, the data were resampled to a regular $1^{\circ} \times 1^{\circ}$ latitude-longitude grid, using a smoothing criterion of $1-\left(r / r_{d}\right)^{2}$, where $r$ is the distance of the actual data point to the fixed grid point, and $r_{d}$ is the radius of search arbitrarily fixed to $2.5^{\circ}$. For AMSU-B, the brightness temperature (BT) data were resampled without smoothing to a regular grid of $0.2^{\circ} \times 0.2^{\circ}$, using a weighting of $1 / r^{2}$, where $r$ is again the distance of the actual data point to the fixed grid point. Consecutive satellite passes covering the domain 
of $10^{\circ}-60^{\circ} \mathrm{N}, 10^{\circ} \mathrm{W}-50^{\circ} \mathrm{E}$ were concatenated in their descending and ascending (approximately between 22000400 and $0800-1300$ UTC, respectively) motions providing a twice-daily BT information for this area.

We use as well wind, SST, snow depth, and skin temperature operational analyses from the ECMWF, rather than the 40-yr ECMWF Re-Analysis (ERA-40) dataset (Uppala et al. 2005), which is available only up to 2002. The horizontal resolution is of $1.125^{\circ} \times 1.125^{\circ}$, and vertical levels range from 1000 to $1 \mathrm{hPa}$ with a total sampling of 21 levels. Although SST can be obtained from satellite infrared and microwave measurements, retrievals are not possible in conditions of cloud cover (for infrared) or rain (for both infrared and microwave; Wentz et al. 2000), which constitutes the situations we are interested in and therefore are not used in the present study.

\section{a. Detection of upper-level troughs}

Funatsu et al. (2007a,b) have shown that AMSU-A channel 8 (A8) can be used for detection of upper-level troughs in the Mediterranean that are frequently observed in the vicinity of heavy precipitating systems. Channel 8 has a weighting function with a peak near $200 \mathrm{hPa}$, therefore sampling the tropopause region during summer and the lower stratosphere during winter. Warm A8 areas were found to be near coincident with areas of high potential vorticity (PV) in the upper troposphere, indicating the presence of air of stratospheric origin. Because BT is not a conserved quantity, dynamical systems cannot be characterized by a single BT threshold, as is easily done for example with potential vorticity. Funatsu et al. (2008) used anomalies of A8 relative to its 6 -yr mean to identify upper-level troughs; they found that an anomaly value of A8 BT (hereafter A8') of $3 \mathrm{~K}$ was nearly coincident with areas with $\mathrm{PV}$ as large or larger than 6 PV units (PVU; 1 PVU $=10^{-6} \mathrm{~K} \mathrm{~m}^{2} \mathrm{~kg}^{-1} \mathrm{~s}^{-1}$ ) at $250 \mathrm{hPa}$. Such high-PV structures were present for example in the vicinity of six events of heavy precipitation in the Mediterranean region (Funatsu et al. 2007b). Here we examine what are the typical $\mathrm{A} 8$ and $\mathrm{A} 8^{\prime}$ values when either nonconvective or deep convective precipitation is present, for each season. Another diagnostic parameter we examine is the BT differences of channels 7 and 5 . This combination of channels can give information on the downward penetration of the upper-level trough (Funatsu et al. 2007b), a less negative value representing a deeper vertical penetration.

\section{b. Detection of rain}

AMSU-B moisture channels (3-5) detect the presence of hydrometeors through the scattering of radiation, which lowers the brightness temperature compared to its surroundings (e.g., Greenwald and Christopher 2002).
Based on this property, Funatsu et al. (2007a,b) showed that a combination of channels 3 and 5 of AMSU-B can detect precipitating areas; a threshold of channels 3 minus $5,(\mathrm{~B} 3 \mathrm{~m} 5) \geq-8 \mathrm{~K}$, was found to correspond statistically to a rainfall of at least $10 \mathrm{~mm}$ in $3 \mathrm{~h}$ when compared to the Tropical Rainfall Measuring Mission (TRMM) 3B42 3-hourly accumulated precipitation product. Because accumulated rainfall spatial distribution is highly variable it is only possible to define the quantile for $10 \mathrm{~mm}$ in $3 \mathrm{~h}$ locally (but not for the basin as a whole). Such a value however leans toward the end tail of the precipitation distribution. For reference, heavy precipitating events in the Mediterranean basin have yielded accumulated rain-

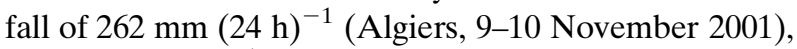
$230 \mathrm{~mm}(24 \mathrm{~h})^{-1}$ (Antalya, 5-6 December 2002), and $690 \mathrm{~mm}(24 \mathrm{~h})^{-1}$ (Nîmes, 8-9 September 2002).

Areas of deep convection are detected using a criterion initially devised to identify convection in the tropical regions (Hong et al. 2005), called the deep convective threshold (DCT). It is defined such that B3m5, B4m5, and B3m 4 (i.e., AMSU-B channels 4 minus 5, and 3 minus 4 , respectively) are simultaneously equal or larger than zero. DCT was found to correspond in the Mediterranean region to an accumulated rainfall of at least $20 \mathrm{~mm}$ in $3 \mathrm{~h}$ in $50 \%$ of the cases also compared with TRMM data. Both thresholds were validated for rain detection in the Mediterranean over surfaces free of snow or ice (Funatsu et al. 2007a,b) with radar and rain gauges from meteorological ground stations for selected heavy precipitating events.

Despite the fact that the water vapor channels are less sensitive to the underlying surface (Deeter and Vivekanandan 2005), over snow-covered areas or very cold surfaces these thresholds alone may underperform in discriminating between frozen hydrometeors and a cold surface under a clear sky. Over such areas, we use an additional constraint that a precipitating region must attain an upper-tropospheric humidity (UTH) relative to ice of at least $70 \%$. This UTH was calculated using AMSU-B channel 3 based on Buehler and John (2005). We tested the precipitation threshold with the additional UTH constraint against freely available precipitation data from the European Climate Assessment and Dataset (ECAD) project (Klein Tank et al. 2002). Two stations were chosen: Zurich, Switzerland $\left(47.38^{\circ} \mathrm{N}\right.$, $8.57^{\circ} \mathrm{E}$, altitude: $556 \mathrm{~m}$ ) and Mount Aigoual, France $\left(44.12^{\circ} \mathrm{N}, 3.58^{\circ} \mathrm{E}\right.$, altitude: $\left.1567 \mathrm{~m}\right)$. These stations where selected because of their high-altitude locations as well as the availability of snow cover data for the Zurich station. $\mathrm{B} 3 \mathrm{~m} 5$ was relaxed to $-9 \mathrm{~K}$ only for this test, based on its standard deviation given in Funatsu et al. (2007b). For Zurich, we selected days from December through March, from 2001 to 2007, where snow depth 
was larger than 0 . Then, among these days (126 days), we searched for days with precipitation larger than 0 (52 days). Only 2 out of the 52 days were detected through the criteria $\mathrm{B} 3 \mathrm{~m} 5 \geq-9 \mathrm{~K}$ and $\mathrm{UTH} \geq 70 \%$ and no false positives were found. Unfortunately, snow depth data is not available for the Mount Aigoual station, but due to the station altitude, we assume that for the period of December-March, either there is snow on the ground or the ground is frozen. For this station, 848 days were considered with 287 days with precipitation. Only 12 days are detected with the same criteria above, among those two false positives. This simple analysis shows that our criteria is rather stringent and results in underestimation of the precipitating events over snowcovered areas or regions of frozen ground. However, it also shows that it restrains the false positives, and therefore the detection of precipitation whenever it occurs can be considered reliable.

\section{Spatial and temporal distribution of rain, deep convection, and upper-tropospheric humidity}

We present the 7-yr average seasonal relative frequency of rain over the Mediterranean basin (Fig. 1, left column). Precipitation in general is widespread over the entire Mediterranean basin, including the sea, in all seasons except summer [June-August (JJA)]. Rain is more frequent in the northern part of the basin, while along the northern edge of North Africa the occurrence of rain is limited to the coastal areas and mountainous regions (Morocco, Algeria). During summer, the coastal regions of Israel and Egypt are generally dry (Fig. 1e). In the latter, dry conditions prevail also in autumn (Fig. 1g). The spatial and temporal representation obtained here is congruent with the monthly rain rate climatology at $2.5^{\circ} \times 2.5^{\circ}$ from the Global Precipitation Climatology Project (GPCP; Adler et al. 2003), which uses a combination of satellite and rain gauge data (Fig. 2, right column). For example, the maxima in frequency and rainfall amount over Croatia and western Turkey in December-February (DJF), in the Alpine region in March-May (MAM) and JJA, and over the Adriatic Sea and coastal areas in the vicinity, as well as in Turkey in September-November (SON) are similar. Minima over Spain in DJF and the absence of significant rainfall over the Levant and northeastern coast of Africa are also captured in both climatologies. Differences are noted for example, over the Alpine area with the absence of significant rainfall in DJF compared to the maximum found in the present climatology, and the maximum occurrence in SON located over Portugal compared to the maximum rainfall amount west of Northern Spain (off the coast) in the GPCP climatology. Notice however that we are comparing two different quantities-the total frequency of precipitation in our study and GPCP seasonally averaged monthly precipitation - with different horizontal resolution, therefore the match between these two spatial distributions is quite remarkable.

The distribution of deep convection (DC) presents an even more pronounced seasonality (Fig. 1, right column), with convective events more frequent over land in summer, spreading toward the sea in autumn, then occurring most frequently over the sea in winter, and again spreading toward land in spring. These results are in agreement with independent studies based on lightning activity that show a similar pattern of seasonal "migration" (e.g., Holt et al. 2001; Christian et al. 2003). This spatial distribution also points to areas where DC is more frequent, for example, the Alpine region, the coastal region of Croatia, the Balearic Islands, south of France, and Tunisia (Fig. 1h). These regions coincide with areas frequently affected by events of heavy precipitation and floods (e.g., the MedEx database; Nuissier et al. 2008). We focus on some of these regions in the following section, in order to examine upper-level conditions as seen by AMSU that characterize events of precipitation with or without deep convection.

An important point to notice is that the rain and DC detection method we use here is insensitive to the landsea contrast. The precipitation distribution showed in Fig. 1 is corroborated by UTH seasonal averages and their variances (Fig. 2, left column). The northern part of the basin (Europe) is nearly twice as humid as that over the African continent and even the southeastern sea. However, the variance is large in all regions except the easternmost Mediterranean during summer, when there is very low UTH and low variance, in agreement with the overall lack of precipitation. During summer there is high variance over or near the orographic relieves such as the Atlas Mountains, the Pyrenees, the Massif Central, and the Alps. During autumn, a large variance covers the central Mediterranean region, following the coastal areas of Spain, France, Italy, Croatia, Greece, Algeria, and Tunisia. Despite the relatively low mean UTH in these regions, the large variance indicates the occasional presence of precipitation in those seasons.

\section{Relationship between precipitation and large-scale features in selected locations}

Here we examine the differences in the large-scale environment that are associated with moderate rain and those with heavy precipitation, in certain regions of the Mediterranean. We separate precipitation events in two "categories": one that produces rain without DC [i.e., nonconvective precipitation (NCP)], and the other, rain 

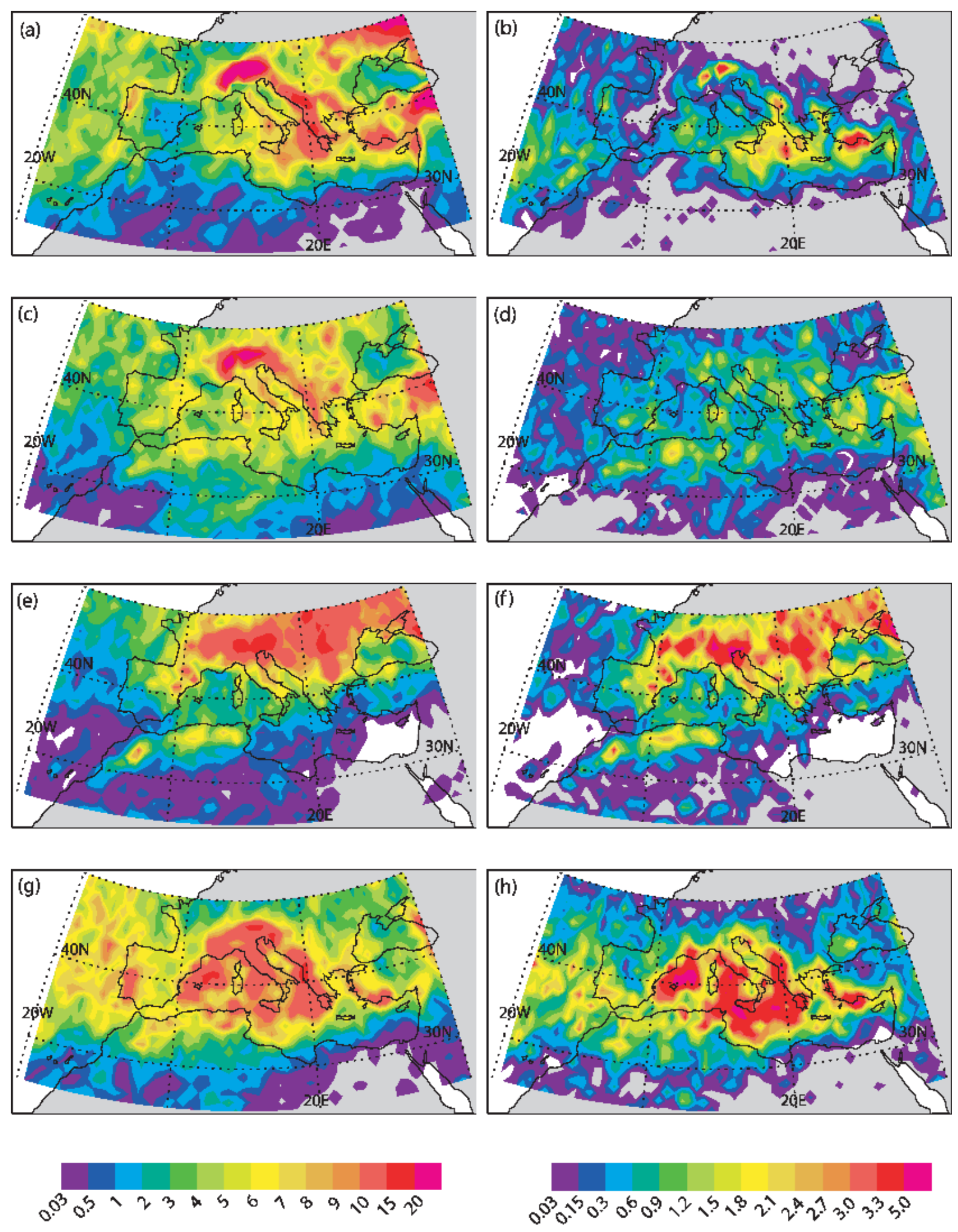

Relative Frequency (\%o)

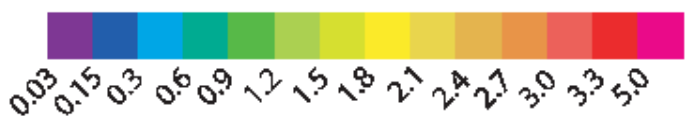

Relative Frequency (\%)

FIG. 1. Spatial distribution of relative frequency (in parts per thousand) of (left) precipitation and (right) deep convection in a $1^{\circ} \times 1^{\circ}$ grid for the period 2001-07: (a),(b) DJF; (c),(d) MAM; (e),(f) JJA; and (g),(h) SON. 

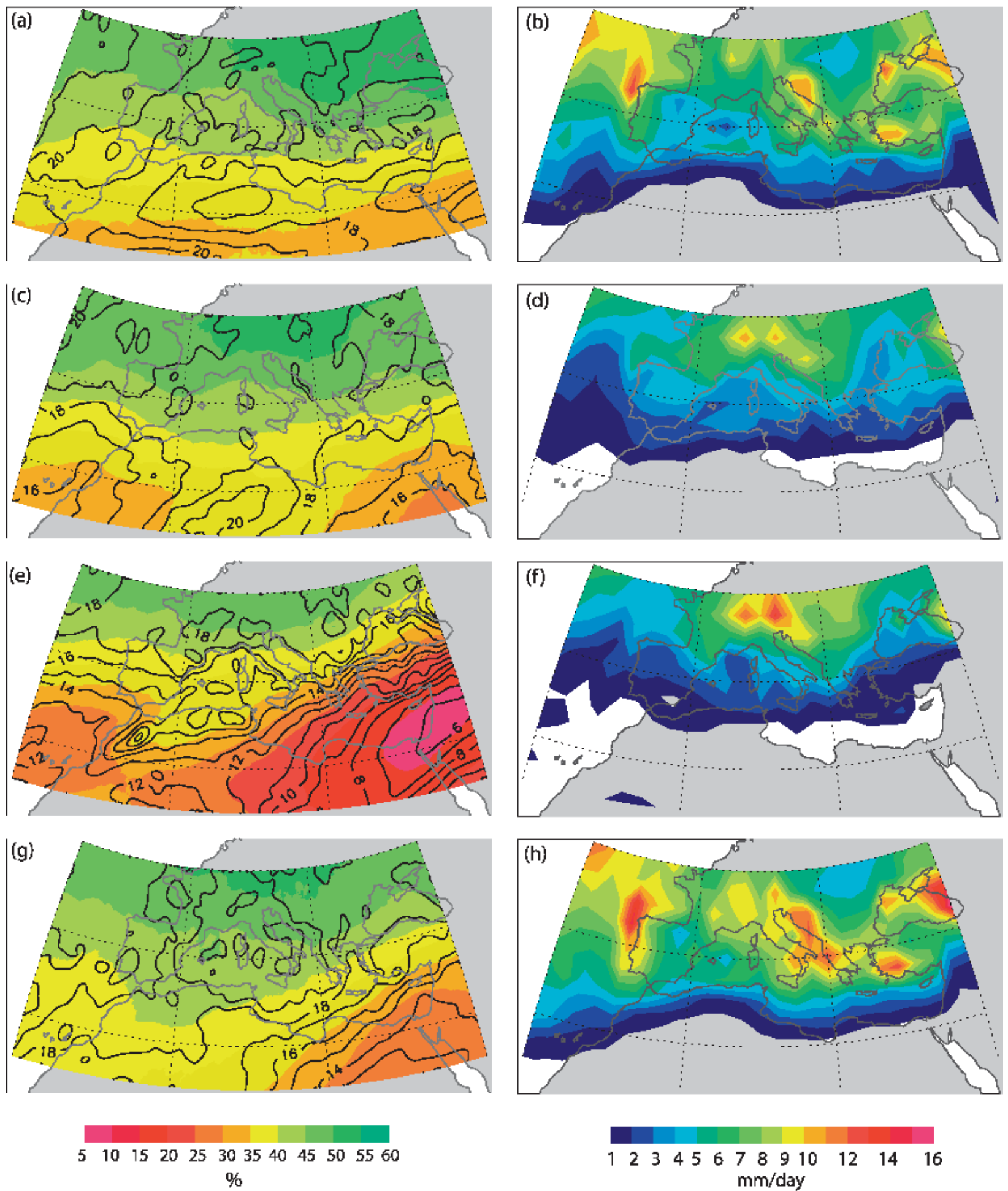

FIG. 2. (left) Average upper-tropospheric humidity (color, \%) and its variance (solid lines, \%) and (right) precipitation (mm day ${ }^{-1}$, $2.5^{\circ} \times 2.5^{\circ}$ ) from the GPCP monthly merged precipitation analysis, for the period 2001-07: (a),(b) DJF; (c),(d) MAM; (e),(f) JJA; and (g),(h) SON. 
with large areas of deep convection embedded, which we refer as "extreme DC" events. Clearly, the same system may produce rain with or without DC at some stage of its evolution. Also, the selection applies to a certain physical (geographical) location, which means that if the system produces deep convection outside the area of interest, it will nevertheless be classified as NCP. The areas selected are frequently affected by heavy precipitation as seen in the climatology presented in the previous section (Fig. 1). We chose distinct areas such that they fall in each of the subdomains defined in Funatsu et al. (2008) (i.e., the northwest, northeast, southwest, and southeast Mediterranean). The domain of search for each region is subjectively defined as follows:

1) Alpine Southside: $43.8^{\circ}-46.4^{\circ} \mathrm{N}, 7^{\circ}-10.6^{\circ} \mathrm{E}$;

2) Southern France: $42^{\circ}-44.6^{\circ} \mathrm{N}, 2.6^{\circ}-7^{\circ} \mathrm{E}$;

3) Tunisia: $34.4^{\circ}-37.4^{\circ} \mathrm{N}, 8^{\circ}-12^{\circ} \mathrm{E}$;

4) Turkey: $35^{\circ}-38^{\circ} \mathrm{N}, 28.2^{\circ}-32.4^{\circ} \mathrm{E}$;

5) Israel and southern Lebanon (ISL): $31^{\circ}-34^{\circ} \mathrm{N}$, $34^{\circ}-37^{\circ} \mathrm{E}$.

Since our rain detection method does not discriminate rain rates, we cannot establish a criterion to detect extremes of precipitation based on rainfall amount. Instead we consider a precipitation event as "extreme" when the area of deep convection $\mathcal{A}$ is equal or exceeds the area covered in $90 \%$ of DCT occurrences. Table 1 shows the area threshold $\left(\mathcal{A}_{c}\right)$ values for each region and season. For example, for the South Alpine region in winter (DJF) in $90 \%$ of the cases where DC is found it covers an area smaller than $4 \%$ of the total area. In this case, if $\mathcal{A} \geq 4 \%$, then this rainfall event is considered an extreme event. Except for the South Alpine region, $\mathcal{A}_{c}$ is larger in autumn (SON) than in other seasons; in Turkey, the seasonal differences between $\mathcal{A}_{c}$ are less pronounced than in other regions. ISL has the largest seasonal differences with extreme events covering areas 3-4 times larger in SON than in DJF or MAM.

Table 2 gives the number of rainfall events, for each region and season, of $\mathrm{NCP}$, rain with $\mathrm{DC}$, and of those for which $\mathcal{A}$ exceeds the threshold $\mathcal{A}_{c}$ given in Table 1 (roughly $10 \%$ of the number of rain events with DC). In all regions, the occurrence of NCP is larger than rain with $\mathrm{DC}$ from winter to spring, and the reverse is observed in summer. In autumn however, NCP and DC occurrences are distinct for the different domains: while in western Europe, NCP is again more frequent than rain with DC, in Tunisia and Turkey the summer pattern is still observed. ISL is the most distinct, with no differences detected in this season; another peculiarity of this region is that in JJA only one event of rain with DC was detected, which could be classified as an extreme rainfall event. Since this case was isolated it may be
TABLE 1. Relative area (\%) covered in $\sim 90 \%$ of cases where DCT is satisfied.

\begin{tabular}{lcccr}
\hline \multicolumn{1}{c}{ Region } & DJF & MAM & JJA & SON \\
\hline South Alpine & 4 & 6 & 7 & 6 \\
Southern France & 4 & 3 & 4 & 10 \\
Tunisia & 4 & 3 & 3 & 9 \\
Turkey & 9 & 7 & 6 & 12 \\
ISL & 4 & 3 & 0 & 13 \\
\hline
\end{tabular}

more interesting to examine it from a case study perspective, and we opted to exclude it in the following analysis. With this methodology, we show for each of these regions the accumulated frequency of rain events and the corresponding composite structures of A8 BT, anomalies of A8 BT relative to a 7-yr monthly mean $\left(\mathrm{A} 8^{\prime}\right)$ and $\mathrm{A} 7 \mathrm{~m} 5 \mathrm{BT}$, by seasons, to examine the differences between the environments leading or not to extreme precipitating events. We also formed composites of wind at $850 \mathrm{hPa}$ and SST, both from the ECMWF operational analyses. For NCP, SST composites were based on dates where the first rain occurrence within 2 days was detected. This procedure was adopted in order to exclude the effect of the precipitation itself on the SST. Although the same can occur for extreme DC events, we form SST composites of all events because of the small number of cases. SST anomalies (hereafter $\mathrm{SST}^{\prime}$ ) were then formed by removing the seasonal mean SST. Spurious gradients are sometimes observed near coastal areas, such as in the Bay of the Seine (Normandy), at the tip of the Brest peninsula, near the Gulf of Venice, and at the eastern side of Cyprus. These small-scale, localized gradients are unrealistic and are not given any further consideration in our analysis.

\section{a. Alpine region}

The Alpine Southside (AS) is a region vulnerable to flash floods following events of heavy precipitation because of its topography and several river catchments (Frei et al. 2001; Jasper and Kaufmann 2003; Walser and Schär 2004). Heavy precipitating events in turn are often associated with elongated streamers over western Europe (e.g., Massacand et al. 1998), and it has been found that the persistence of these features to the west of the Alps increases the probability of large accumulated rainfall in the AS (Martius et al. 2006). The intensity of the precipitation is largely controlled by the moisture content of the low-level air, and in fact a strong moisture flux across the southern AS boundary is a key element for the occurrence of extreme precipitation in the region (Hoinka et al. 2006; Martius et al. 2006). This flux is influenced by the strength and position of an upper-level feature (Fehlmann et al. 2000). 
TABLE 2. Absolute number of events with (a) NCP, (b) rain with DC, and (c) DC exceeding the area threshold given in Table 1.

\begin{tabular}{|c|c|c|c|c|c|c|c|c|c|c|c|c|}
\hline \multirow[b]{2}{*}{ Region } & \multicolumn{3}{|c|}{ DJF } & \multicolumn{3}{|c|}{ MAM } & \multicolumn{3}{|c|}{ JJA } & \multicolumn{3}{|c|}{ SON } \\
\hline & (a) & (b) & (c) & (a) & (b) & (c) & (a) & (b) & (c) & (a) & (b) & (c) \\
\hline South Alpine & 256 & 50 & 8 & 220 & 76 & 9 & 118 & 160 & 18 & 134 & 69 & 8 \\
\hline Southern France & 114 & 24 & 3 & 129 & 41 & 6 & 78 & 88 & 10 & 102 & 86 & 9 \\
\hline Tunisia & 102 & 57 & 6 & 79 & 72 & 9 & 61 & 75 & 10 & 90 & 121 & 14 \\
\hline Turkey & 116 & 109 & 12 & 91 & 64 & 7 & 15 & 27 & 3 & 49 & 89 & 9 \\
\hline ISL & 56 & 33 & 4 & 45 & 25 & 4 & 0 & 1 & 0 & 17 & 17 & 2 \\
\hline
\end{tabular}

From a climatological standpoint, Frei and Schär (1998) and Frei et al. (2003) have shown using gridded precipitation analyses for the period of 1971-90 and 1979-93, respectively, that the mean precipitation and its frequency in the Alpine region is larger at its foothills mostly along the northern edge in both DJF and JJA; however, there is seasonal variation, with precipitation more frequent on the northeast side in JJA, and more in the northwest edge (French Alps) in the DJF. Frei et al. (2003) also showed that the 90th quantile of daily precipitation in SON is found mostly at its southeastern side, as well as at the valley between the Massif Central and southwestern Alps.

Figure 3 shows the absolute frequency of NCP (Figs. 3a-d) and extreme DC events (Figs. 3e-h), indicating the geographical location of precipitation. NCP is distributed mostly along the northern (Alpine ridge) and southern (Mediterranean coast) parts of the domain; the location of deep convection however varies sharply from season to season. In wintertime, the occurrence is confined to the Alpine ridge and its vicinity, while for the rest of the year it is distributed along the entire domain. In particular, in JJA extreme DC is found south of the Alpine ridge and to the east of the domain (Fig. 3g). These results are in close agreement with the climatology presented by Frei et al. (2003), for example, compare Fig. 3h (SON absolute frequency of extreme DC) with their Fig. 12 (90th quantile daily precipitation in SON). This further indicates that although our analysis is based on a relatively short time span of $7 \mathrm{yr}$ it captures the general climatological precipitation distribution.

The large-scale environments in which these rain events are embedded are represented in Fig. 4, which shows the seasonal composites of $\mathrm{A} 8$ and $\mathrm{A} 88^{\prime}$ fields for NCP (left panel) and extreme DC cases (right panel). Except for DJF, there is a thinner, more pronounced A8 ridge (corresponding to a pressure trough) located upstream of the affected area, with at least $1 \mathrm{~K}$ larger in the extreme DC cases compared to those found in the NCP composites. Similarly, Chaboureau and Claud (2006) found, using a ground-based climatology of precipitation and using $8.5 \mathrm{yr}$ of TOVS satellite data, that events in the Alpine region yielding large accumulated totals have a thin, elongated trough to the west of the Alps, while those with lower precipitation amounts have a broader trough, found more to the northwest.

In DJF, a cutoff-low-like A8 feature is seen in both cases (Figs. 4a,b), but with larger area and larger amplitude in the extreme DC case. In the NCP composites the cutoff low is centered at around $40^{\circ} \mathrm{N}, 5^{\circ} \mathrm{E}$, to the southwest of the affected area, while in the extreme DC case, the maximum A8 is found north of Sicily, to the southeast of the intense rainfall. In all seasons, the corresponding $\mathrm{A} 8^{\prime}$ field is of at least $1.5 \mathrm{~K}$ (and much warmer from September to February, Figs. 4b,h), while the anomalies are rather feeble for the NCP cases. The trough is more defined and deeper in the extreme DC cases (Fig. 4) as well, for example, with A7m5 values above $-20 \mathrm{~K}$ for extreme DC cases in DJF, while for NCP the trough is ill-defined and has values up to $-23 \mathrm{~K}$ (Figs. 4a,b). Another relevant aspect regarding $\mathrm{A} 8^{\prime}$ is that for all seasons, there is a pronounced wavelike pattern, with alternating cold and warm $\mathrm{A} 88^{\prime}$ centers (Fig. 4, right column).

In particular the $\mathrm{A}^{8} \mathrm{BT}^{\prime}$ configuration in SON (Fig. 4h) indicates that the vertically deep upper-level feature induces a moisture-rich southwesterly flow at low levels impinging over the Alps. This is confirmed by the wind composites at $850 \mathrm{hPa}$ (Fig. 5h), and is also observed for MAM and JJA. SST' and low-level winds for NCP cases are weak in all seasons; from March to November SST' are around $0.5-1 \mathrm{~K}$ larger in extreme DC events than in the NCP events. The warmer sea and stronger winds induce stronger low-level surface fluxes that contribute to the maintenance of deep convection.

\section{b. South of France}

The southern coastal area of France is one of the rainiest regions in western Europe (Frei and Schär 1998), and frequently affected by devastating flash floods (e.g., the MedEx database; Sénési et al. 1996; Delrieu et al. 2005; Nuissier et al. 2008). Observational and numerical simulation studies have shown that a combination of a slow evolving synoptic system (mesoscale convective systems, cold fronts, etc.), the surrounding mountain relief, low-level circulation, and an ample supply of 
(a) $\pi=256$

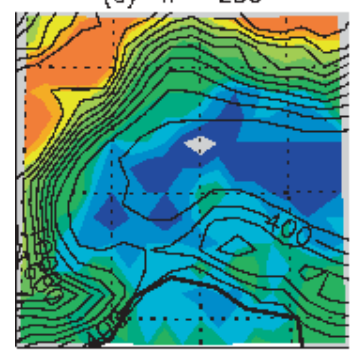

(e) $\mathrm{n}=8$

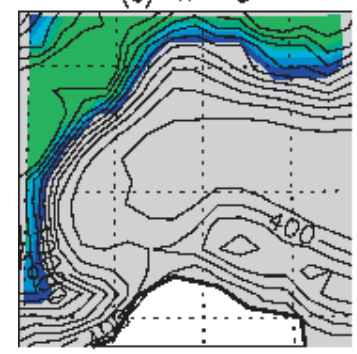

(b) $n=220$

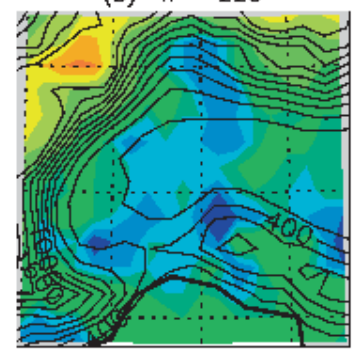

(f) $n=9$

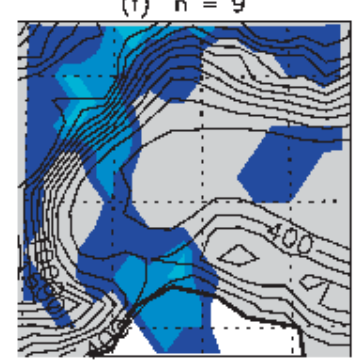

(c) $\mathbf{n}=118$

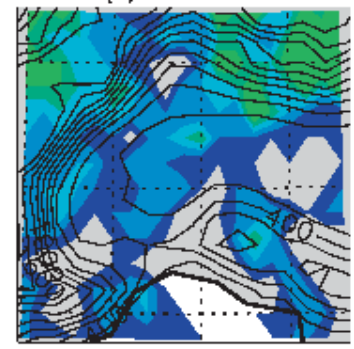

(g) $n=18$

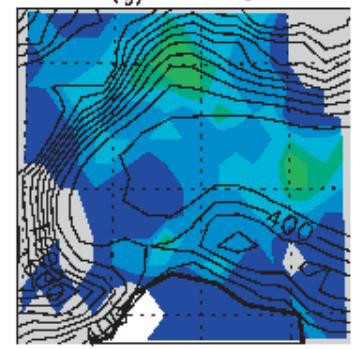

(d) $\pi=134$

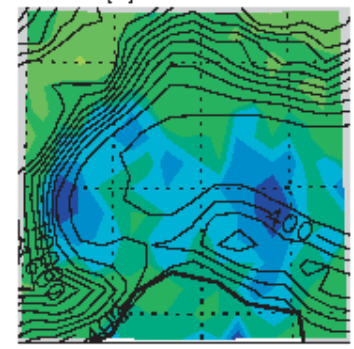

(h) $n=8$

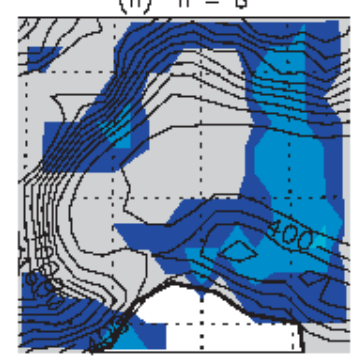

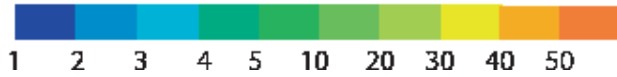

FIG. 3. Absolute frequency of (a)-(d) NCP and (e)-(h) extreme DC, with a resolution of $0.2^{\circ} \times 0.2^{\circ}$, for the AS $\left(43.8^{\circ}-46.4^{\circ} \mathrm{N}\right.$, $\left.7^{\circ}-10.6^{\circ} \mathrm{E}\right)$ : (a),(e) DJF; (b),(f) MAM; (c),(g) JJA; and (d),(h) SON. Topography isolines are shown every $200 \mathrm{~m}$. Here $n$ denotes the total number of events.

moisture led to persistent, heavy precipitating events in this region.

NCP is found near the Alpine relief, at the northeast corner of the domain, but also spread throughout the domain (Figs. 6a-d). Extreme DC events on the other hand are roughly found equally over land as well as over sea (Figs. 6e-h). Except in JJA, the large-scale environment leading to extreme events is characterized by a thin, elongated trough like area of high $\mathrm{A} 8$ and high $\mathrm{A} 8^{\prime}$ to the west or northwest of the affected are, as opposed to broader and "colder" troughs found in situations where only rain is present. The A8 can be up to $4 \mathrm{~K}$ higher when larger DC areas are found (e.g., Fig. 7b) and $A 8^{\prime}$ is at least $50 \%$ stronger for cases leading to extreme events. Again an alternating, stronger high-low A $8^{\prime}$ pattern is clearly seen for the cases of extreme DC (Fig. 7, right column). The upper-level trough is much deeper in the extreme DC events, as seen in the A $7 \mathrm{~m} 5$ composites in all seasons except SON, and the contrast is remarkable mostly in DJF and MAM (Figs. 7a-d).

Low-level winds are strong $\left(\sim 10 \mathrm{~m} \mathrm{~s}^{-1}\right.$ or more), south-southeasterly, for fall and winter for the extreme DC composites, compared to the southerly flow of about 3-5 m s${ }^{-1}$ for NCP cases (Figs. 8a,b,g,h). SST' is $1-2 \mathrm{~K}$ warmer in the extreme DC events composites compared to those of NCP in all seasons but DJF, where SST' is only slightly positive in the vicinity of the affected area for the extreme DC composites. As in the case of the Alpine Southside, SST' and 850-hPa wind composites for NCP cases are weak in all seasons.

The striking differences in the 850-hPa wind and SST ${ }^{\prime}$ for extreme DC and NCP events also suggest that surface fluxes have an important role on the occurrence and/or maintenance of such extreme events. This is consistent with the results of Lebeaupin et al. (2006) who have demonstrated through numerical experiments of three cases of extreme precipitation in southern France that a warmer SST increases the intensity of convection and precipitation amounts, by increasing the turbulent near-surface heat fluxes that moisten and destabilize the atmosphere up to $3 \mathrm{~km}$.

\section{c. Tunisia}

The Mediterranean coastal region of North Africa is affected by heavy precipitating systems (e.g., the 2001 storm in Algiers and Morocco; Tripoli et al. 2005; Funatsu et al. 2007b; Argence et al. 2008), however their climatology is less known than for western Europe. Funatsu et al. (2008) have found that precipitation (with or without DC) in the southwest region of the Mediterranean basin occurs more than $75 \%$ of the cases whenever an $\mathrm{A} 88^{\prime}$ feature of at least $3 \mathrm{~K}$ was found in the vicinity, 

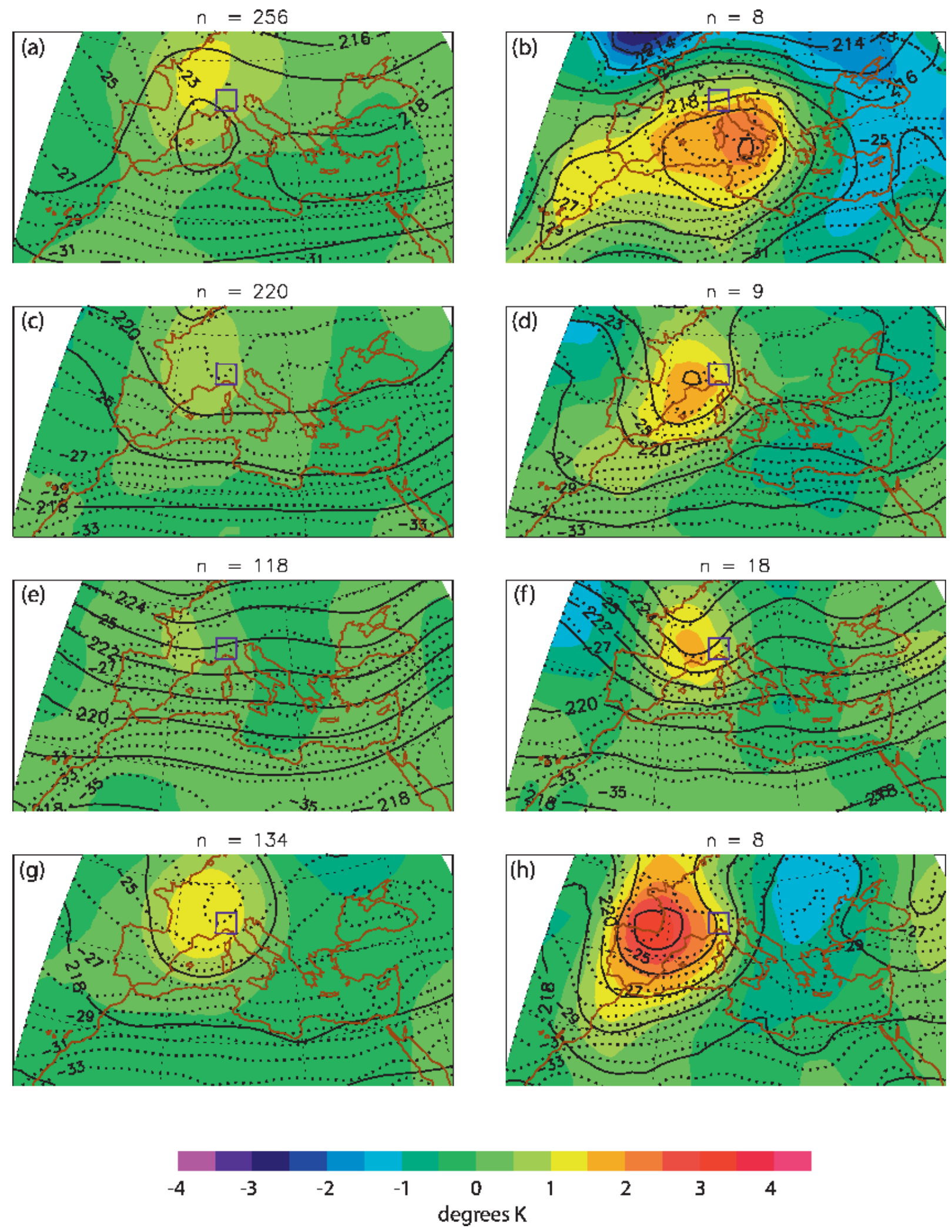

FIG. 4. The AS A8 (solid lines), A7m5 (dotted lines), and A8' (colored) composites for (left) NCP and (right) extreme DC events: (a),(b) DJF; (c),(d) MAM; (e),(f) JJA; and (g),(h) SON. All composites are shown in kelvin units. 
suggesting a strong association between the upper-level forcing and the occurrence of precipitation regardless of the season. However, for deep convection, they found that this association presents a seasonal cycle, being more frequent in summer and early autumn, and less frequent in spring, and there is large interannual variability. Notice though that these results were averaged for a relatively large area, and the occurrence of precipitation was examined when an upper-level feature was present; here, we investigate upper-level features when there is precipitation.

NCP is widespread throughout the domain in all seasons, with less occurrences in summer (Figs. 9a-d); similarly, extreme DC occurrences do not show preferred locations (Figs. 9e-h). A feature of high A8 and A 8 ' upstream (Fig. 10) is present for both rain and extreme DC cases, as in the previous two regions. However, in winter and spring, the location of the structure is more to the southwest of the affected area, rather than to the west or northwest as seen before (Figs. 10b,d). The trough is deeper in the extreme DC cases compared to those of NCP, with differences up to $2 \mathrm{~K}$ (warmer when trough is deeper) in all seasons except SON, where the trough is in fact as deep in the NCP cases as in extreme DC. Also, although the number of cases of extreme $\mathrm{DC}$ is larger in $\mathrm{SON}, \mathrm{A} 8^{\prime}$ is less than $1.5 \mathrm{~K}$, a rather small value compared both to other seasons, and also to the $\mathrm{A} 8^{\prime}$ found for $\mathrm{AS}$ and south of France regions. Therefore, an A8 or A8' trough of smaller amplitude compared to the previous cases (Alpine Southside and south of France) is capable of disturbing the atmosphere and promoting heavy precipitation.

The low-level flow composites show a different picture from the previous cases as well: the differences between NCP and extreme DC are large both in the intensity of the wind, and also in its direction (Fig. 11). For example, in DJF and MAM, winds at $850 \mathrm{hPa}$ are weak (less than $5 \mathrm{~m} \mathrm{~s}^{-1}$ ) and mostly westerlies in the NCP composites. For the extreme DC cases, though, a clear closed circulation can be seen to the southwest of Tunisia, and prevailing winds are from south-southeast and reaching close to $10 \mathrm{~m} \mathrm{~s}^{-1}$. In SON, winds are very feeble in the NCP composites. They are mostly southerlies for extreme DC cases and a low-level closed circulation is not as well defined. While for NCP cases $\mathrm{SST}^{\prime}$ are very weak, for extreme $\mathrm{DC} \mathrm{SST}^{\prime}$ are positive in DJF and SON, while negative in $\mathrm{JJA}$. This rather counterintuitive result in JJA might be explained by the dates of extreme DC occurrence: from the 10 cases, 6 occurred in June, 3 in July, and 2 in August, therefore, most cases occurred in the beginning of the season when SST was still below the seasonal average. This suggests that in JJA extreme DC events in this region are less influenced by SST'.

\section{d. Southern coast of Turkey}

The southern coast of Turkey is a region prone to severe weather events (e.g., the storm in Antalya in December 2002; Kotroni et al. 2006). The steep Taurus Mountains surrounding the Antalya bay and running parallel to the coastline of Turkey consists of an orographic barrier against which moist air is lifted producing persistent rainfall (Kurupinar 1995; Karaca and Dobricic 1997; Alpert et al. 1999; Kotroni et al. 2006).

Figure 12 shows that NCP is more frequent over land, at the upper-half of the domain, while extreme DC is found more evenly distributed over the domain. Summer occurrences are the smallest for both cases, but extreme DC is more frequent in autumn and winter, in agreement with findings of Porcù et al. (2003).

As in the previous regions, $\mathrm{A} 8$ and $\mathrm{A} 88^{\prime}$ composite fields for Turkey also show a distinctive upper-level trough that is narrower or a cutoff low that is more intense for extreme DC than for NCP cases (Fig. 13). The vertical penetration of the troughs as depicted by $\mathrm{A} 7 \mathrm{~m} 5$, shows that these features are "deeper" and spatially more localized in the extreme DC cases, and this aspect seems to be more important than the BT values themselves. For example, from autumn to spring, A7m5 BT in the vicinity of the affected region was about the same value for both NCP and extreme DC cases $(\sim-23 \mathrm{~K}$ in $\mathrm{DJF}, \sim-25 \mathrm{~K}$ in MAM, and $\sim-26 \mathrm{~K}$ in SON), however, the local maxima was located to the west and slightly more to the south than in NCP cases. These apparently small differences have an important impact on whether intense precipitation will be produced.

The Aegean Sea is one the most active cyclogenetic regions in winter (Alpert et al. 1990; Trigo et al. 1999, 2002) and cyclogenesis there are commonly associated with upper-level troughs crossing central Europe (e.g., Jacobeit 1987; Trigo et al. 2002). The 850-hPa wind composites for extreme DC show consistently a closed cyclonic circulation centered over the Aegean Sea, bringing about a strong southerly flow in excess of $10 \mathrm{~m} \mathrm{~s}^{-1}$ in DJF, MAM, and SON (Fig. 14). Much weaker south or southwesterlies of about $3 \mathrm{~m} \mathrm{~s}^{-1}$ for the same seasons are found for NCP cases. SST' composites show a strong seasonal variation for the extreme DC cases, with positive anomalies in DJF and weak or negative anomalies for the other seasons. NCP SST' composites however show consistently weak anomalies throughout the year, except in SON where $\mathrm{SST}^{\prime}$ anomalies are negative. In JJA SST $^{\prime}$ anomalies are more negative in the extreme DC composites than in NCP cases, and like for the case of Tunisia, the explanation may be because of the three extreme DC cases occurred in June and early July, when SST is still colder than its seasonal value. This suggests 


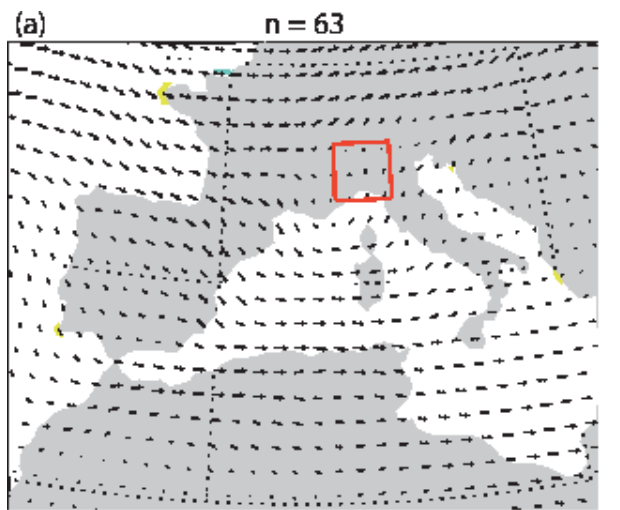

(c)
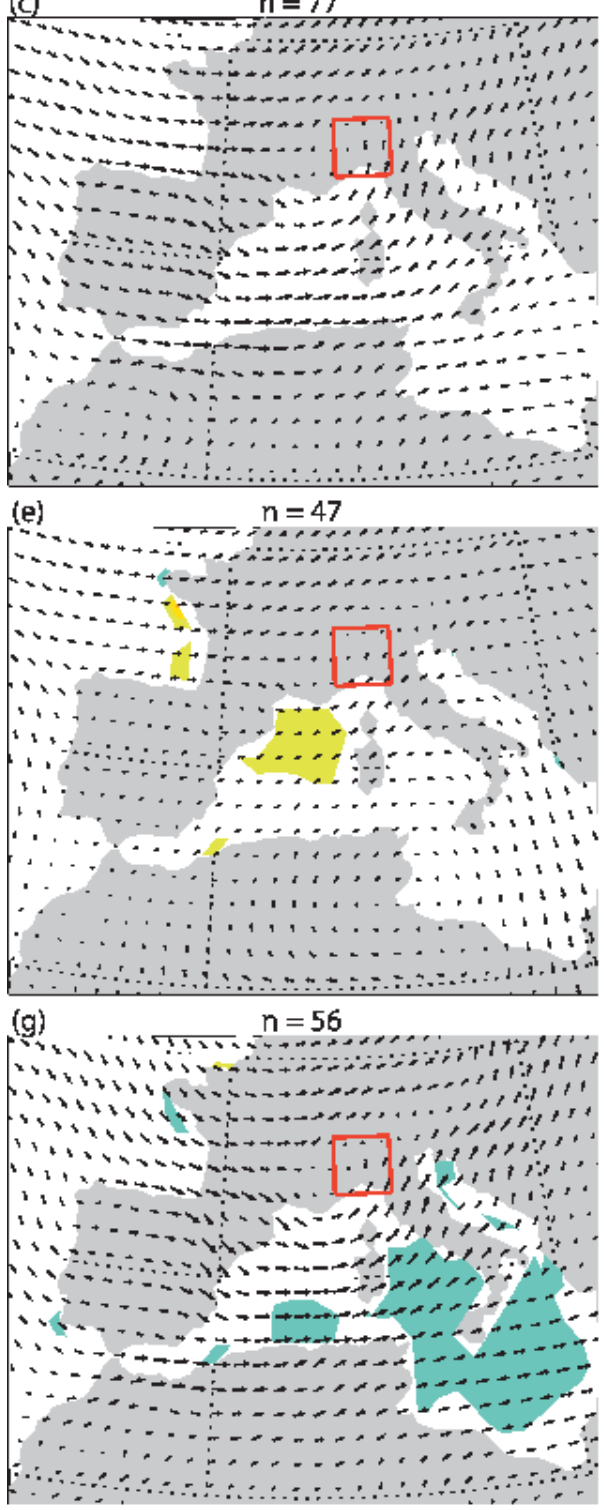

(b)

$\mathrm{n}=8$
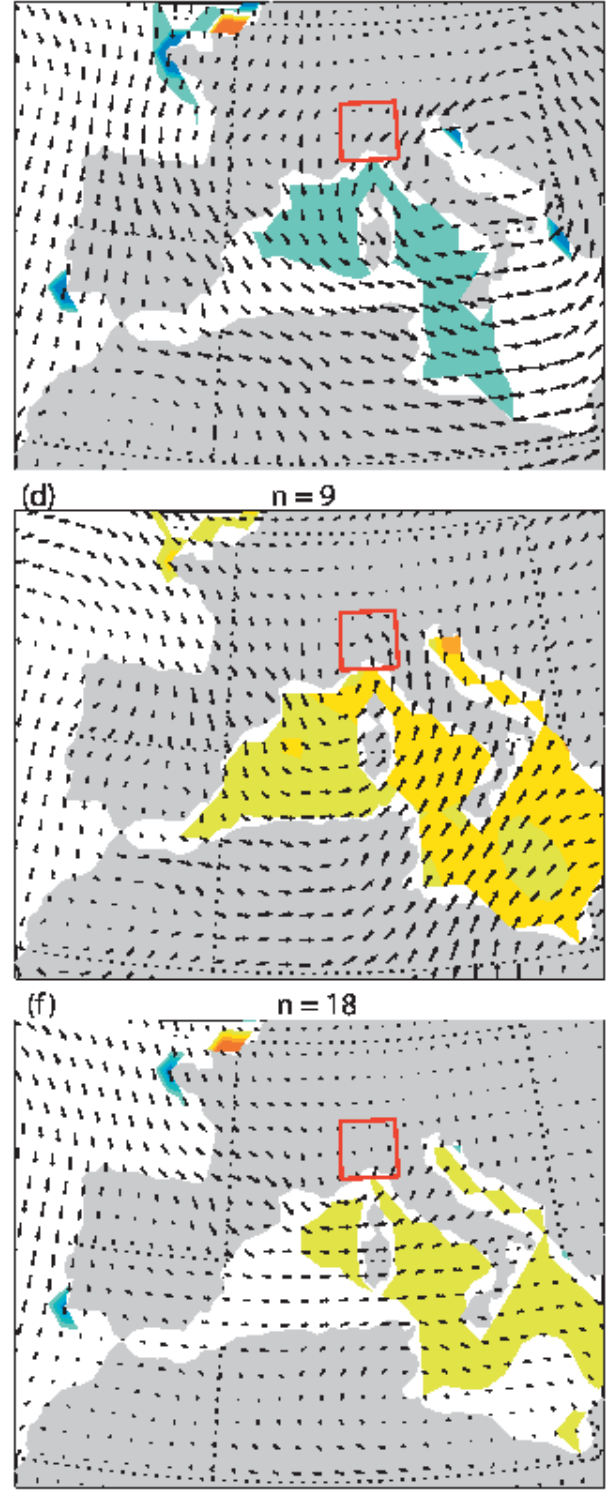

(h) $\quad n, n=8, \ldots \ldots+n+1+\ldots$

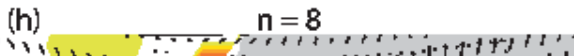
(1) 3 . fisis,

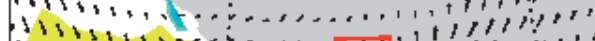

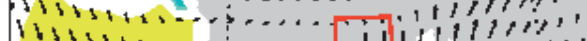
औbis b. tilis

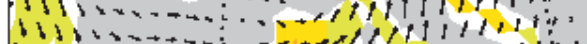

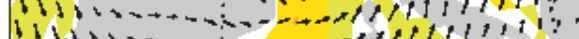

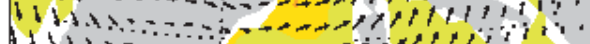
1 1 1 V

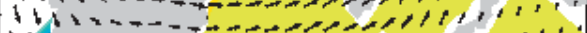

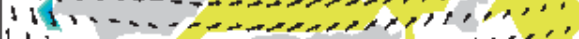

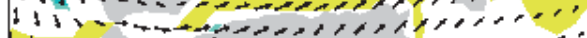

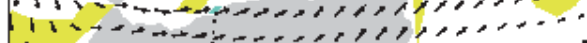
1 、 . - = - . ….... 1.:-

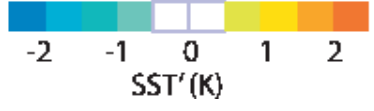


(o) $n=114$

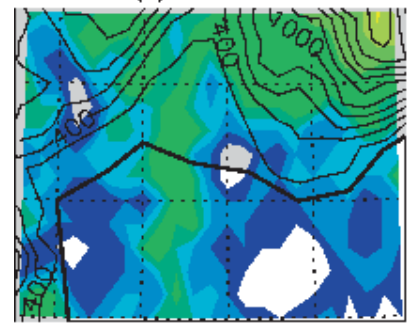

(e) $n=3$

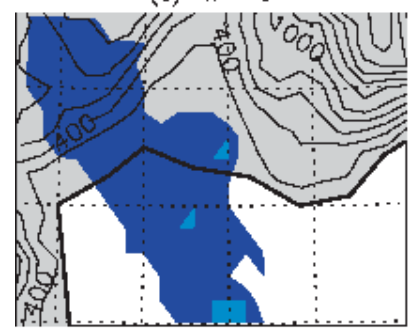

(b) $n=129$

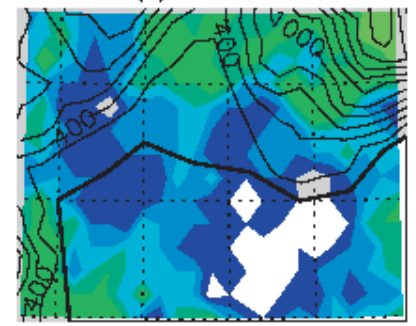

(f) $n=6$

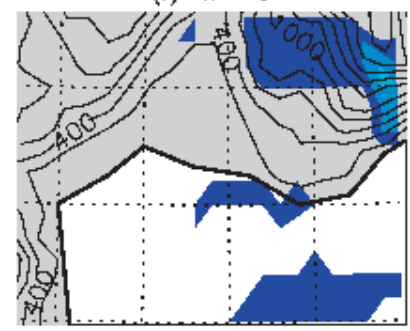

(c) $n=78$

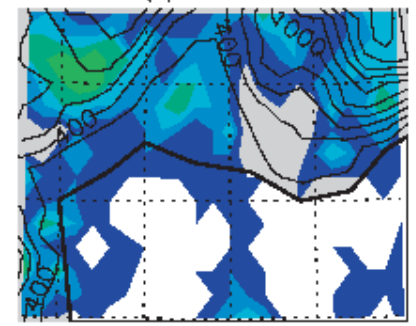

(g) $\mathrm{n}=10$

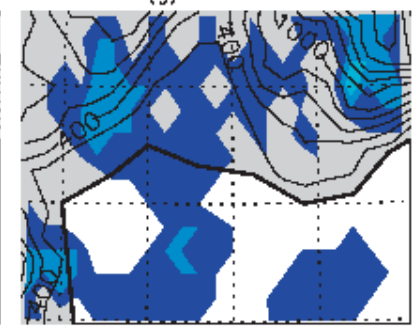

(d) $n=102$

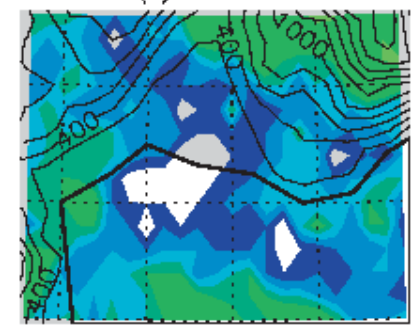

(h) $n=9$

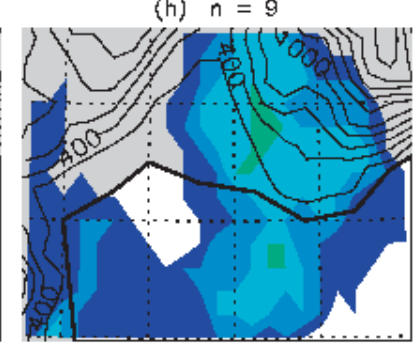

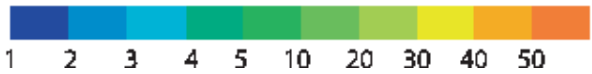

FIG. 6. As in Fig. 3, but for southern France $\left(42^{\circ}-44.6^{\circ} \mathrm{N}, 2.6^{\circ}-7^{\circ} \mathrm{E}\right)$.

that surface fluxes play a role in winter and spring in the occurrence of extreme DC in this area.

\section{e. Israel and southern Lebanon}

The total number or rain events in Israel and south Lebanon is substantially smaller than in western Europe. Rain in general is more present in winter and spring, and rare and sporadic in summer, in agreement with the climatological record, as pointed out by Krichak et al. (2000), Saaroni and Ziv (2000), Ziv et al. (2004, 2006), and Tsvieli and Zangvil (2007). Both NCP and extreme DC events are more concentrated in the northern part of the basin (Fig. 15) in winter and spring; the frequency of events is lower in autumn (see also Table 2).

Differences between NCP and extreme DC events in the $\mathrm{A} 8$ and $\mathrm{A} 88^{\prime}$ configurations are rather marked (Fig. 16), with a distinct trough-ridge-trough train in SON and MAM, with the westernmost trough (large A8 and positive $A 8^{\prime}$ ) over Spain or France, a ridge or col near de Balkans, and finally a pronounced low pressure system in the vicinity of the affected region. In NCP events, a broad region of A8 around $219-220 \mathrm{~K}$ is seen centered over the eastern Mediterranean, to the west of Israel, and $\mathrm{A} 88^{\prime}$ anomalies do not exceed $1.5 \mathrm{~K}$ as opposed to anomalies of up to $3 \mathrm{~K}$ found in the composites for extreme DC. A7m5 show also a well-defined trough with slightly warmer BT for extreme DC cases; in addition, a well-defined (vertically) deep trough is also evident over western Europe.

$\mathrm{SST}^{\prime}$ for extreme DC cases is only slightly warmer in DJF, comparable in MAM, and more negative in SON than in NCP cases (although for SON both composites show negative anomalies; Fig. 17). Low-level winds are southwesterlies (DJF) or westerlies (MAM), but not significantly more intense than in the NCP cases, while for SON winds are weak southerlies (from the desert). On the other hand, NCP events and rain with DC (but not extreme cases) have similar low-level conditions with west to southwesterlies at $850 \mathrm{hPa}$ affecting the target area, and without large discrepancies in the SST distribution (not shown). Thus, there are not very important differences at low levels that distinguish NCP

FIG. 5. The AS composites of SST anomalies (SST') relative to their seasonal mean (color, K) and wind vectors at $850 \mathrm{hPa}\left(\mathrm{m} \mathrm{s}^{-1}\right)$ for (left) NCP and (right) extreme DC events: (a),(b) DJF; (c),(d) MAM; (e),(f) JJA; and (g),(h) SON. For all panels a $1^{\circ}$ length vector corresponds to a wind speed of $10 \mathrm{~m} \mathrm{~s}^{-1}$. 

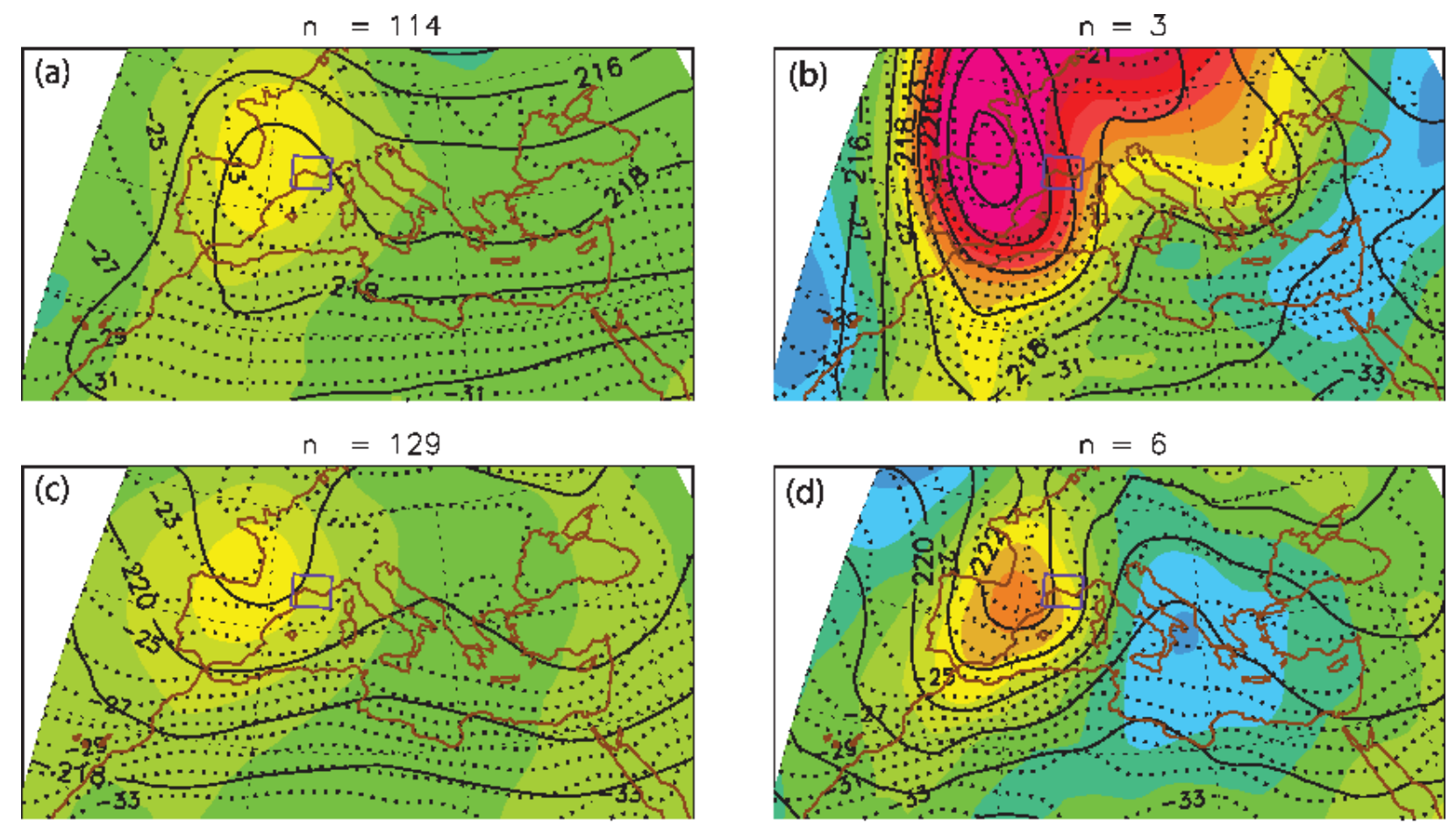

$n=78$
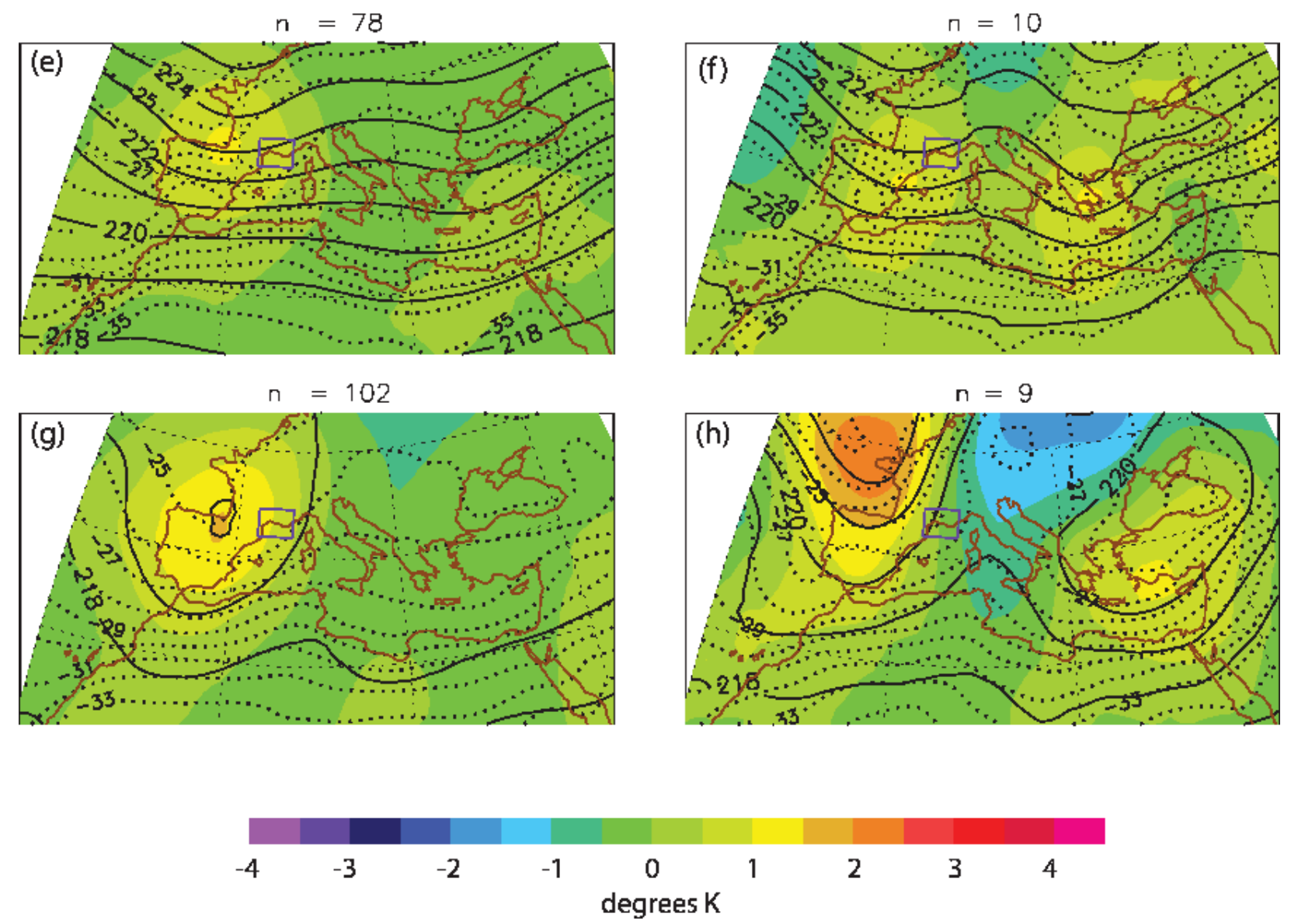

FIG. 7. As in Fig. 4, but for southern France. 
(a)

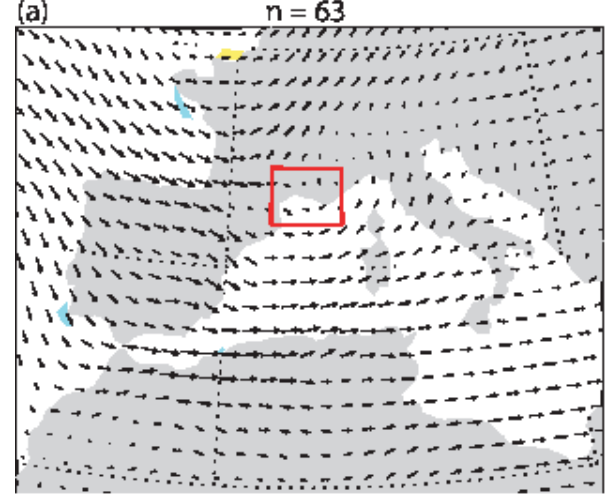

(c) $\mathrm{n}=67$

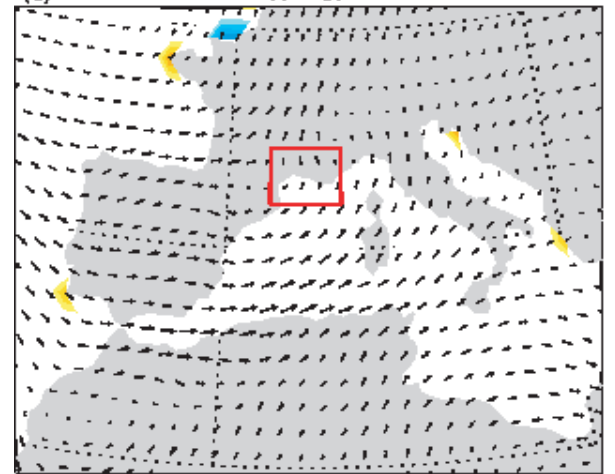

(e)

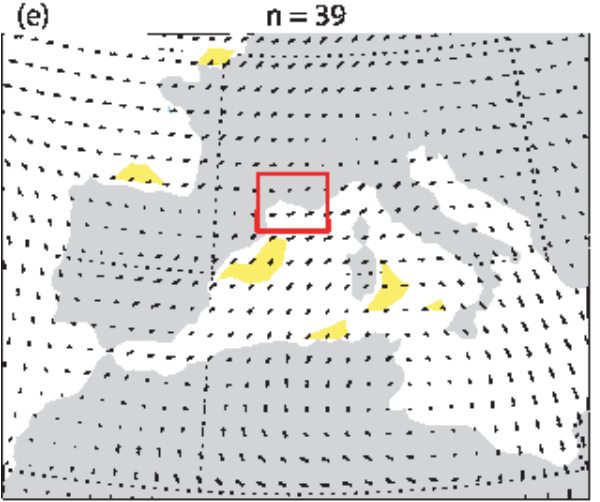

\section{(g) $n=53$}

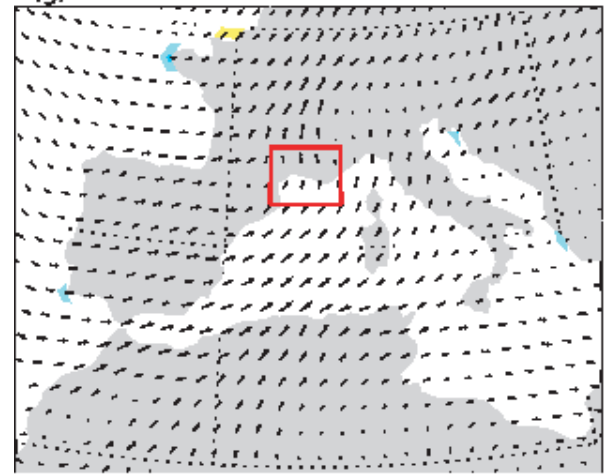

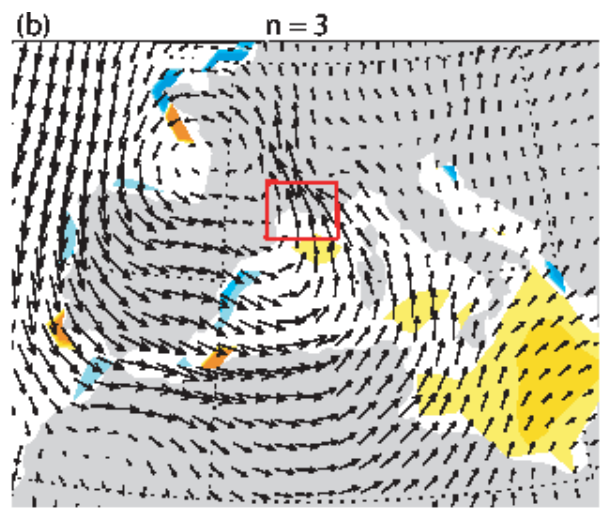

(d)

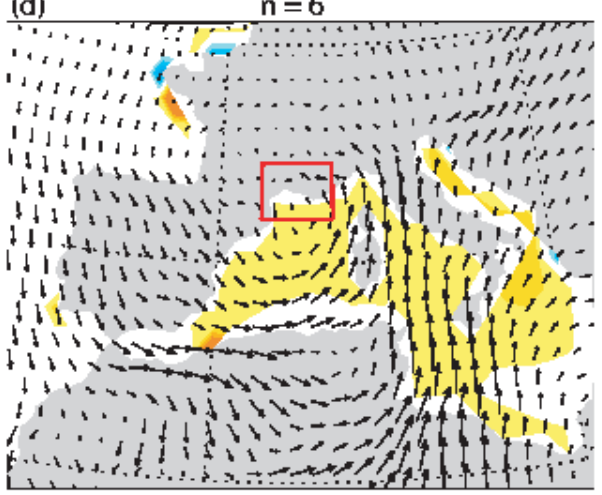

(f) $\mathrm{n}=10$

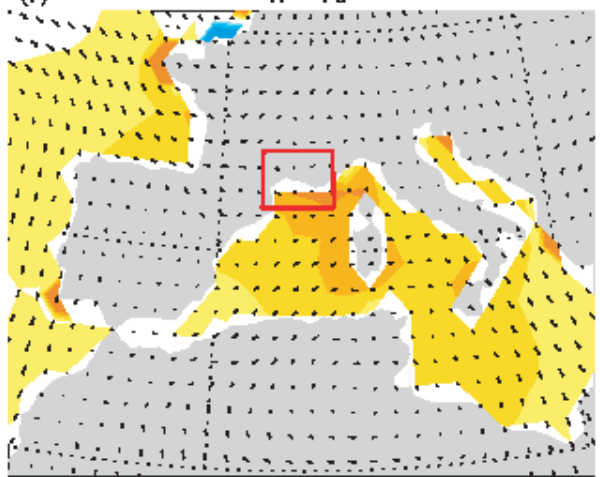

(h)

$$
\mathrm{n}=9
$$

पhen

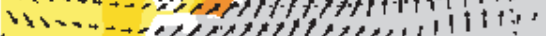
WV=Q hx

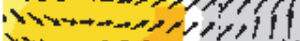

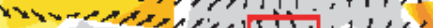

var-1,

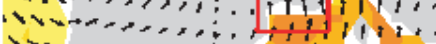

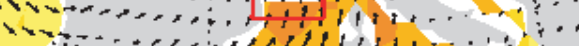

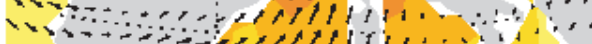

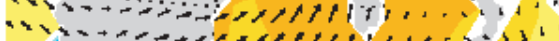

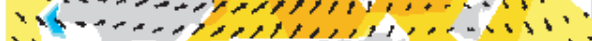
$\therefore=-+\infty,-1,1,1,1, \ldots . .13$ $\because-\infty+\infty+\infty, 1,1,1,1, \ldots$ s

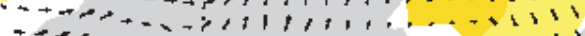

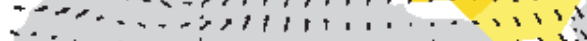

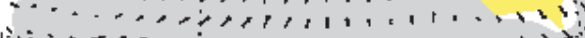

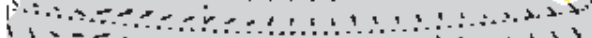

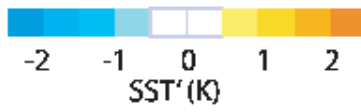

FIG. 8. As in Fig. 5, but for southern France. 
(a) $\mathrm{n}=102$

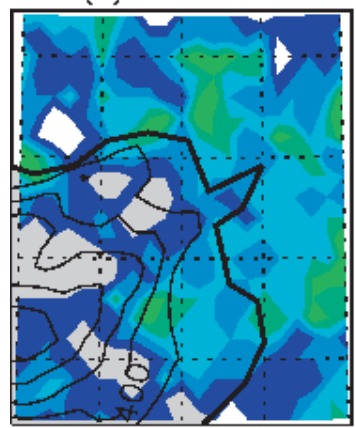

(e) $\Pi=6$

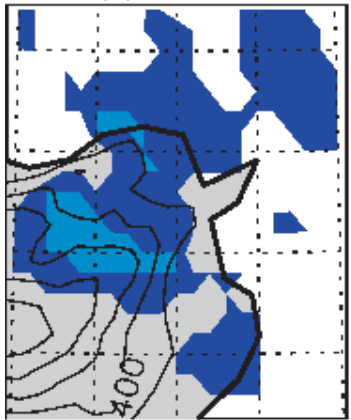

(b) $\mathrm{n}=79$

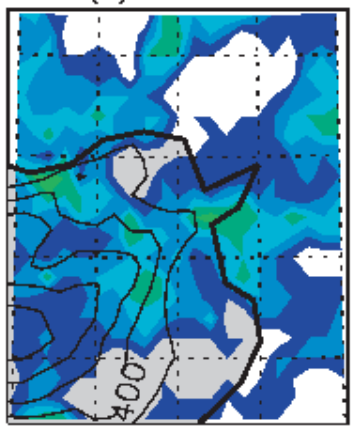

(f) $\mathrm{n}=\mathrm{9}$

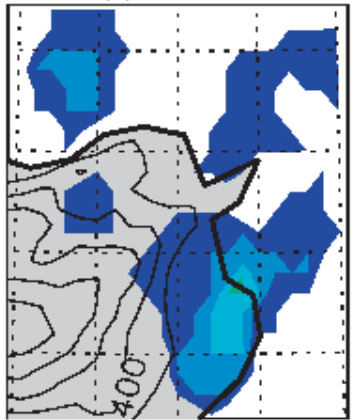

(c) $n=61$

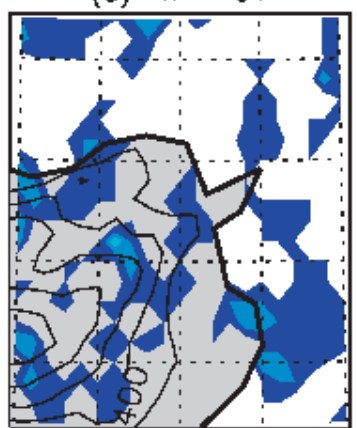

(g) $n=10$

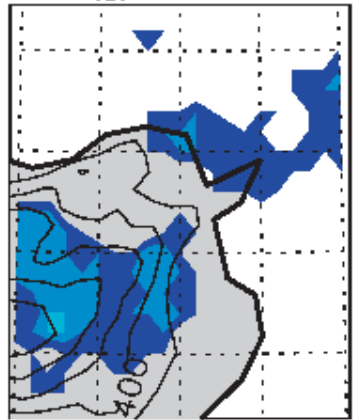

(d) $\mathrm{n}=90$

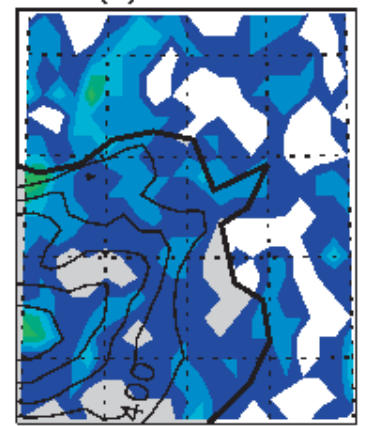

(h) $n=14$

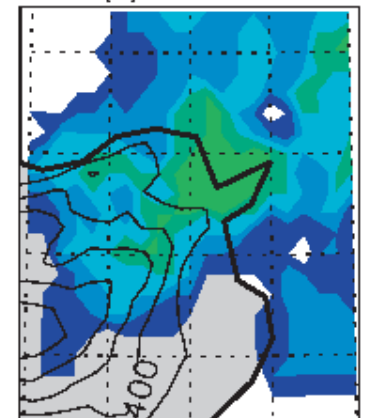

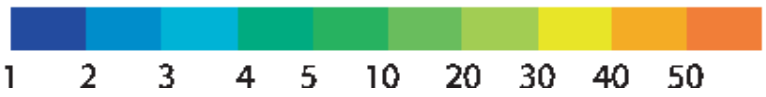

FIG. 9. As in Fig. 3, but for Tunisia $\left(34.4^{\circ}-37.4^{\circ} \mathrm{N}, 8^{\circ}-12^{\circ} \mathrm{E}\right)$.

events or rain with deep convection. This was also noted by Ziv et al. (2006) who explained that both rainfall and rainfall anomalies in the southern Levant can be related in nearly all cases to the presence of a Cyprus low (Sharon and Kutiel 1986; Alpert et al. 1990), an extratropical cyclone that approaches the region from the west, although in our composites a clear low-level circulation corresponding to this feature is not immediately evident in MAM. Extreme events in this area are particularly challenging to characterize because of the relatively low number of rainfall events in general.

\section{Summary and discussion}

We present here a satellite-based view of the largescale environment of precipitating systems over the Mediterranean region. We use diagnostic tools based on the Advanced Microwave Sounding Unit (AMSU) data, both for detecting precipitation (AMSU-B) as well as characterizing upper-level features (AMSU-A). In addition, ECMWF operational analysis of SST and wind at $850 \mathrm{hPa}$ are used to complete the general view of the large-scale environment associated with precipitating events. This study contributes to the effort of identifying and quantifying the sources of uncertainties that affect the forecast and climate projection in the Mediterranean region, in particular for events of extreme rainfall.

In a first step, we provided an overall picture of the rainfall and DC distributions as captured by AMSU-B channels 3-5. We use a simple method, insensitive to land-sea contrast, to detect rain and deep convective occurrence in the Mediterranean basin. Rain occurrence (with or without convection) is widespread over the Mediterranean from autumn to spring; however, precipitation and convection are reduced or short lived in the eastern part of the basin in summer (Fig. 1). There is a clear pattern of seasonal shift in the location of convective precipitation: it is found mostly over land from April to August, and mostly over the sea from September to December (Fig. 1, right column), in agreement with global and regional climatologies of lightning (e.g., Holt et al. 2001; Christian et al. 2003). Increase of convective activity over the sea may be linked to increase in SST, as it was also observed for the tropical oceans (Rondanelli and Lindzen 2008). The precipitation distribution is also overall congruent with the climatology of 

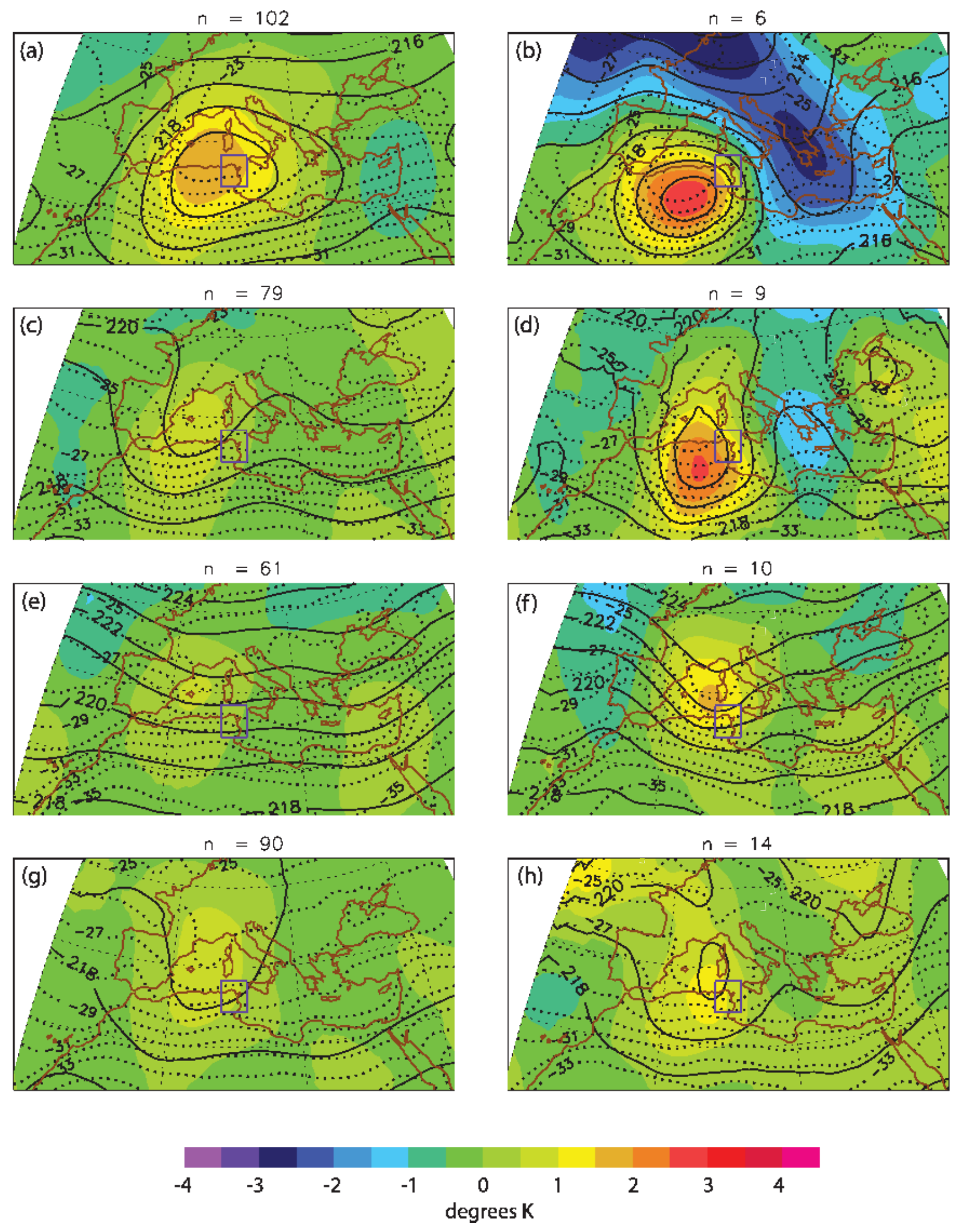

FIG. 10. As in Fig. 4, but for Tunisia. 

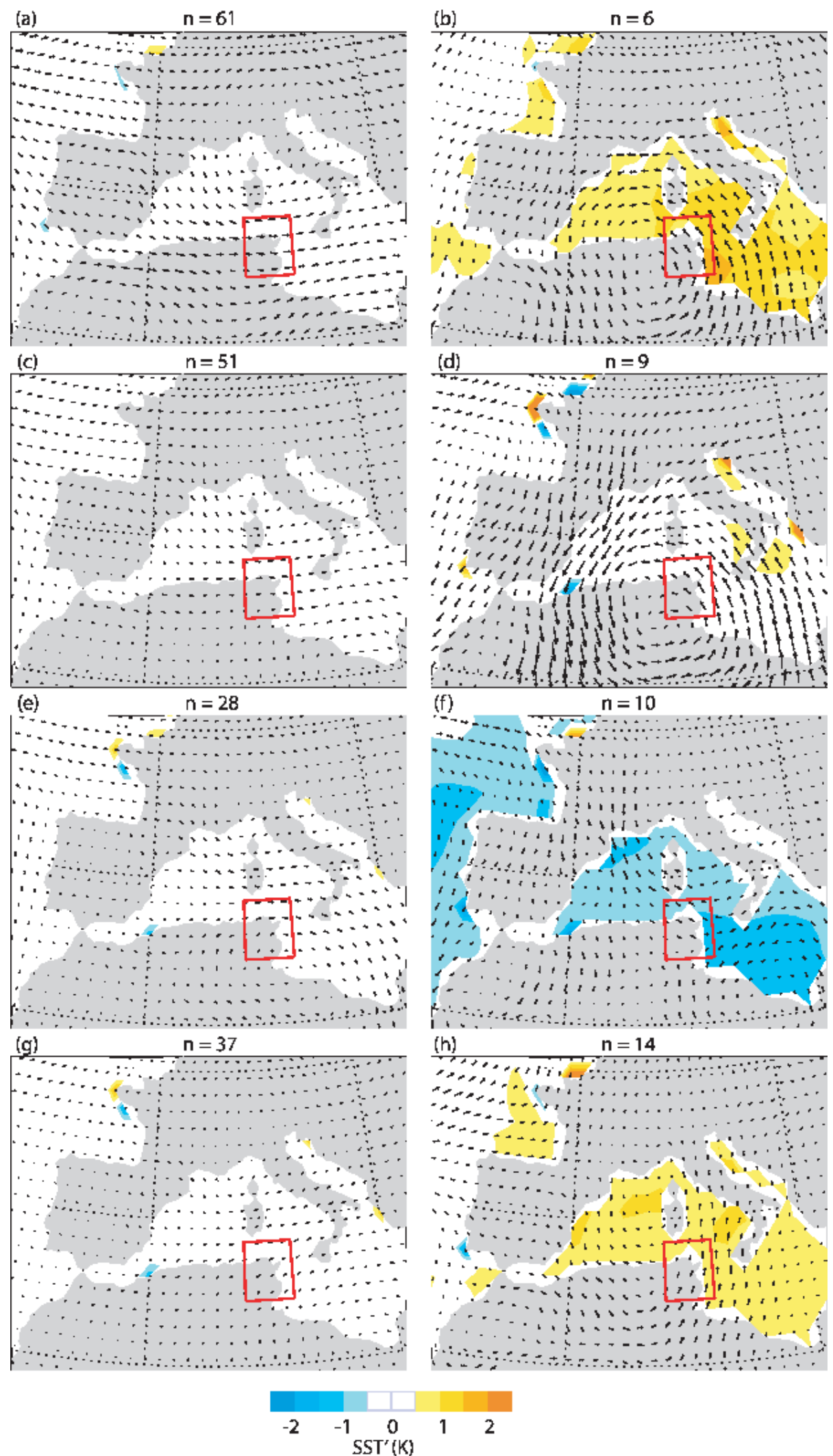

FIG. 11. As in Fig. 5, but for Tunisia. 


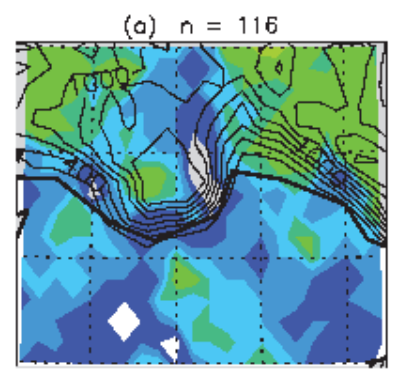

(e) $n=12$

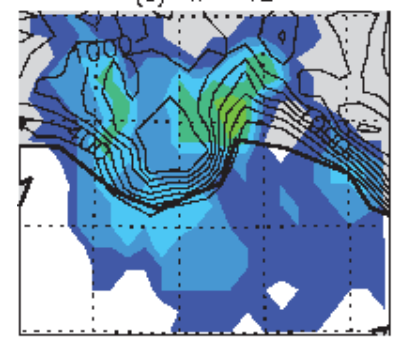

(b) $n=91$

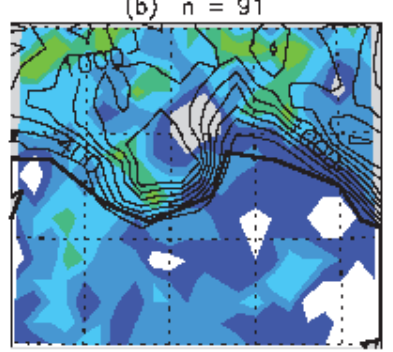

(f) $n=7$

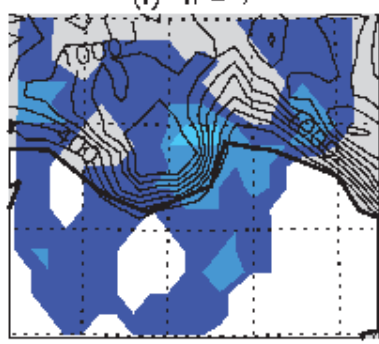

(c) $n=15$

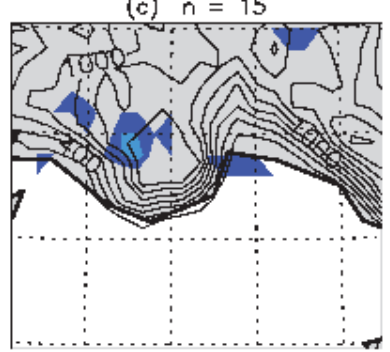

(g) $n=3$

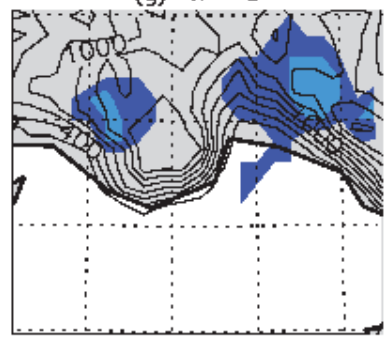

(d) $n=49$

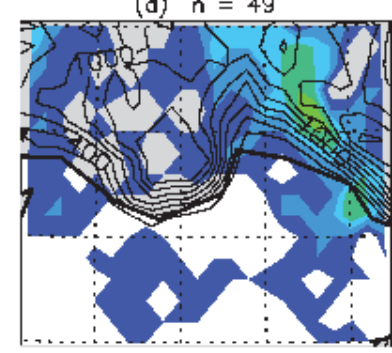

(h) $n=9$

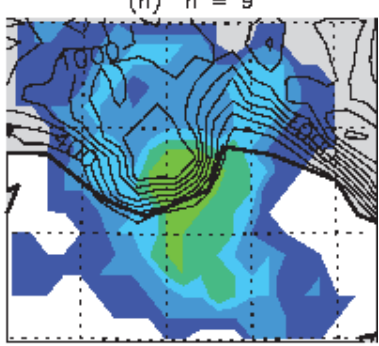

FIG. 12. As in Fig. 3, but for Turkey $\left(35^{\circ}-38^{\circ} \mathrm{N}, 28.2^{\circ}-32.4^{\circ} \mathrm{E}\right)$.

rainfall amounts provided by the Global Precipitation Climatology Project.

In a second step, we selected areas where deep convection is frequent, and formed composites of the upperlevel large-scale conditions described through A8, A8' (warm or positive areas identifying troughs), and $\mathrm{A} 7 \mathrm{~m} 5$ (giving information on the vertical penetration of a trough), as well as SST anomalies relative to its seasonal mean and near-surface winds from the operational ECMWF fields. The selected areas are such that they cover a region in each of the four quadrants in the Mediterranean basin: western Europe, northern Africa, northeastern Mediterranean, and southern Levant.

The number of cases to form composites of extreme DC events is rather small. This can raise questions on the robustness of the results. To examine this issue, we repeated the composite analysis taking the 20 largest DC cases, and we found that in regions where the number of convective precipitation events is large (e.g., the Alpine Southside), composites using either criteria did not differ markedly from each other. However, in regions or seasons where the number of convective precipitation events is barely above (or even below) 20, differences are at times more accentuated. This is particularly true for the case of Israel (see Table 2). These differences stem from the fact that by taking 20 DC events we are mixing in situations where DC is not extensive (not an extreme event). In addition, the low number of cases using our threshold derives partially from the fact that we only use $7 \mathrm{yr}$ of AMSU data. As the dataset gets longer, more events can be added and the results presented here may be extended.

The selected areas in western Europe-the Alpine Southside and southern France-are prone to severe weather leading to heavy rainfall and floods, and are well documented in previous studies. Our results confirm that in autumn, a narrow, well-defined trough is present to the west of the affected region, with a corresponding positive and large $\mathrm{A} 8^{\prime}$. In winter, these troughs are distinctly deeper (vertically), as seen in through A7m5. However these configurations do not reflect any large circulation pattern or a specific weather regime (Barnston and Livezey 1987; Vautard 1990; Sanchez-Gomez et al. 2008). Sanchez-Gomez and Terray (2005) have shown that intense precipitating episodes in western France are not associated with a particular weather regime, being better explained in the frame of weather regime transition. As transient disturbances affect the planetary-scale waves, they promote the change of one weather regime to another. In the case of western France, they found that intense precipitation events in autumn project markedly onto the Zonal-to-Greenland Anticyclone transition, in which a strong low pressure at $500 \mathrm{hPa}$ centered west of Ireland dominates much of northern Europe. This feature is not observed in our composites, however SON A8' composites for both the Alpine Southside and southern France resemble phase 8 of the European-Mediterranean 

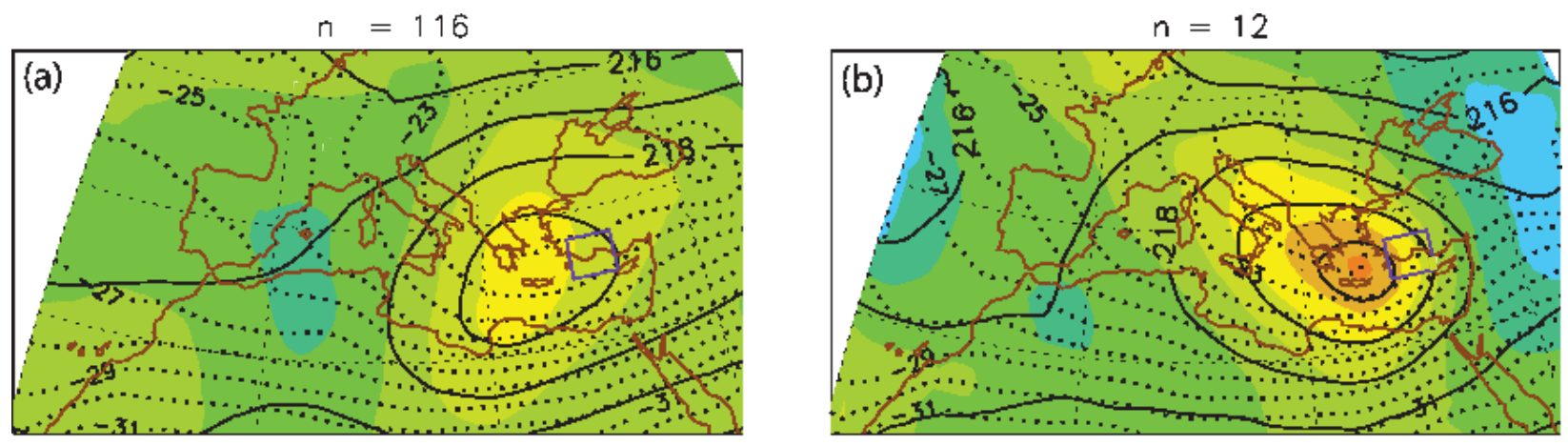

$$
n=91
$$
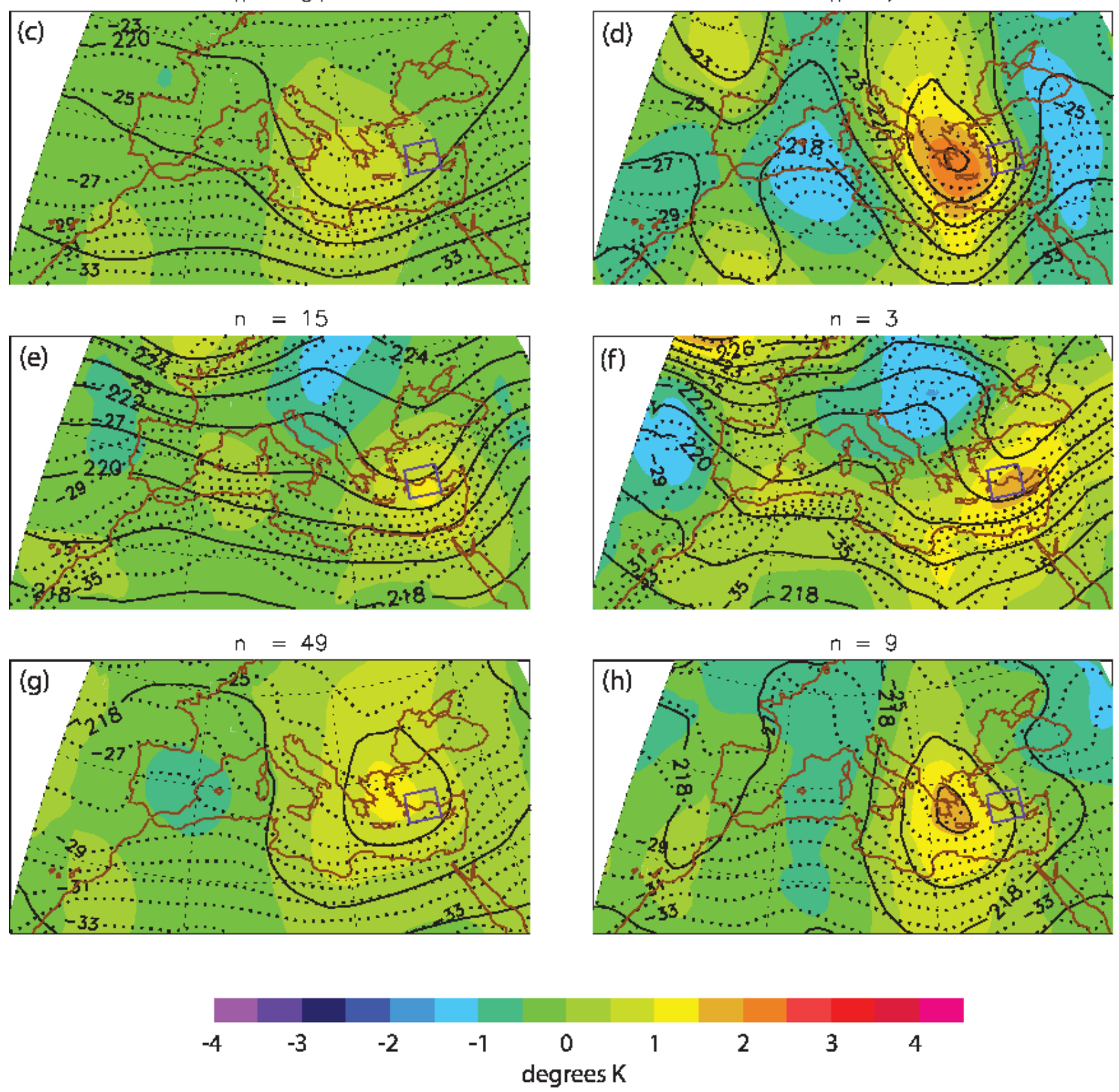

FIG. 13. As in Fig. 4, but for Turkey. 
(a)

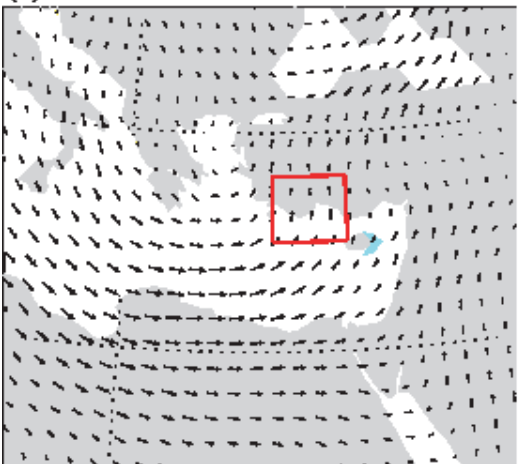

(c)

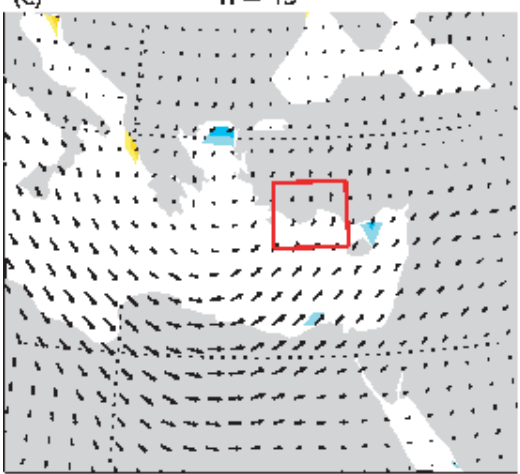

(e) $n=7$

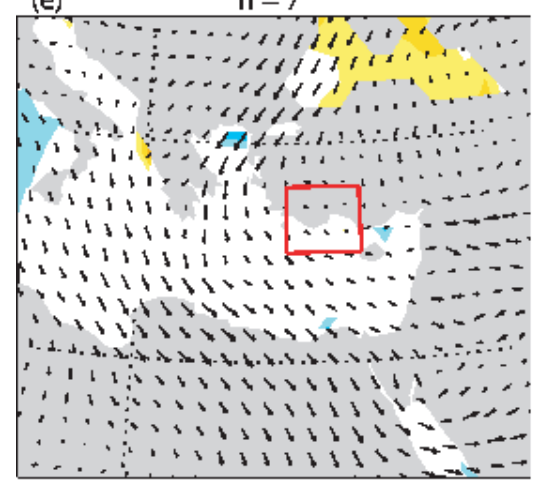

(b)

$\mathrm{n}=12$

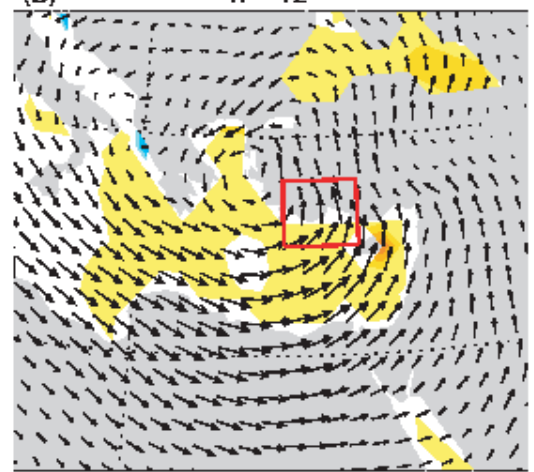

(d)

$n=7$

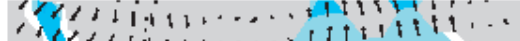

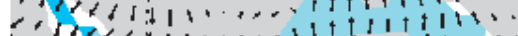

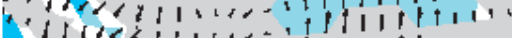

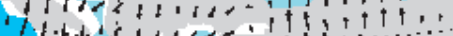
+

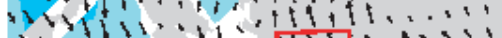

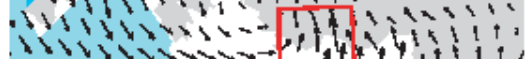

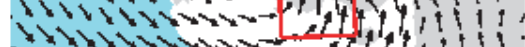

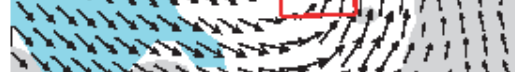

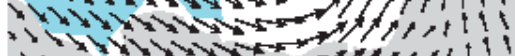

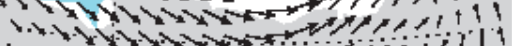
is

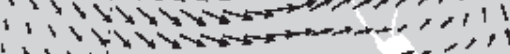
$\because \because 14 x+2 y+\cdots+\cdots$
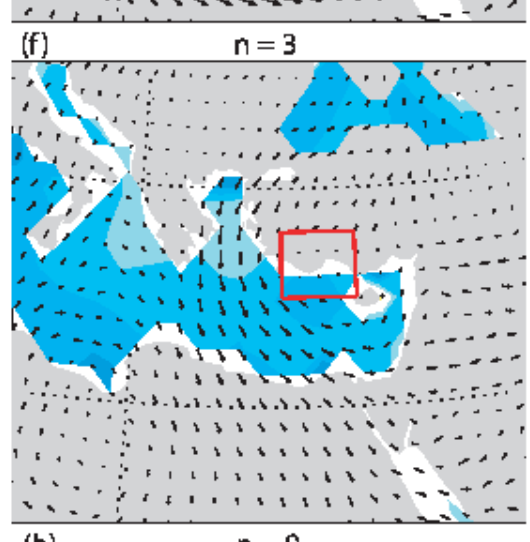
(h)

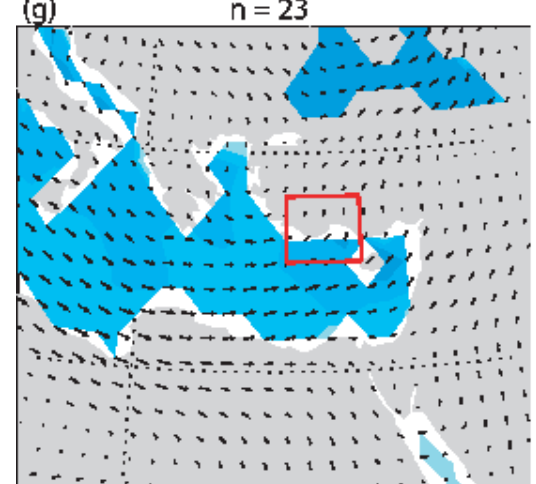

(h) $\frac{n=9}{1, \ldots, 1, \ldots, \ldots, 1, \ldots}$
.1.

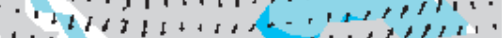

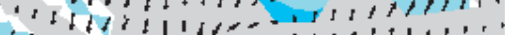

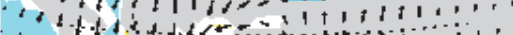

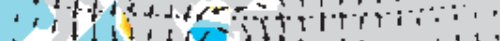

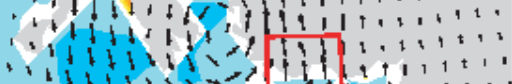

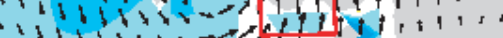

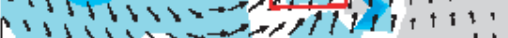

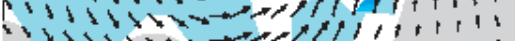

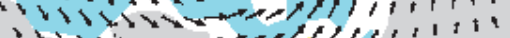

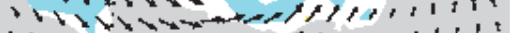
कA 1 -

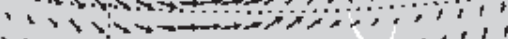

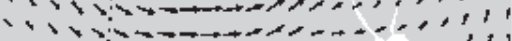

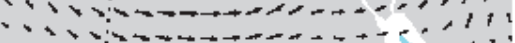

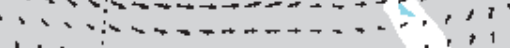

\section{$\begin{array}{llcll}-2 & -1 & 0 & 1 & 2\end{array}$}

FIG. 14. As in Fig. 5, but for Turkey. 
(a) $n=56$

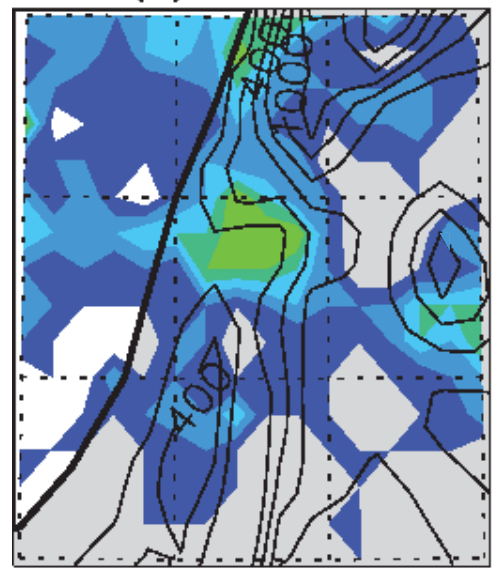

(d) $n=4$

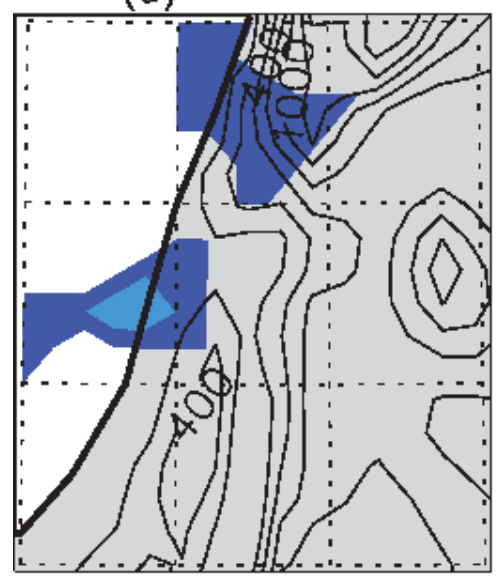

(b) $n=45$

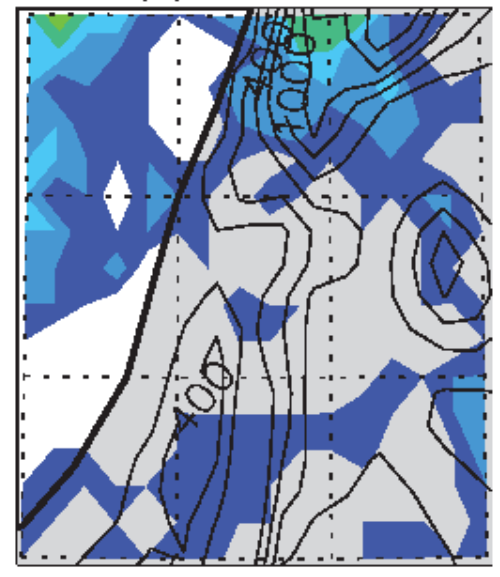

(e) $\mathrm{n}=4$

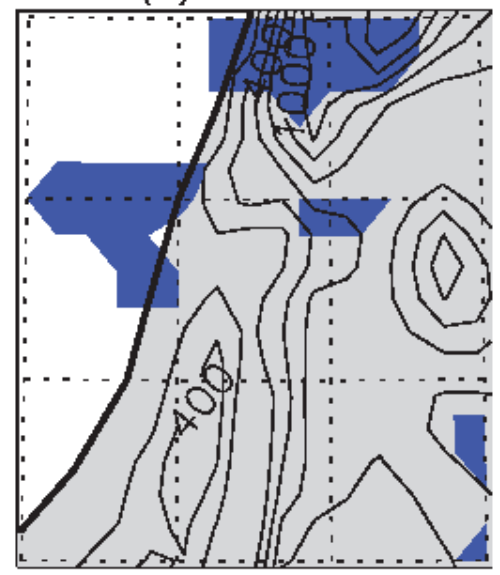

(c) $n=17$

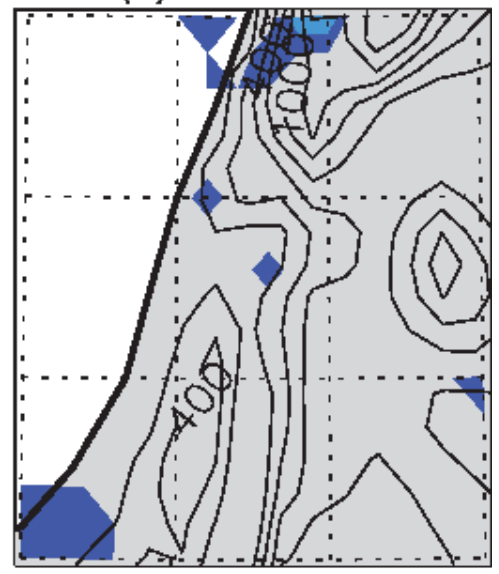

(f) $n=2$

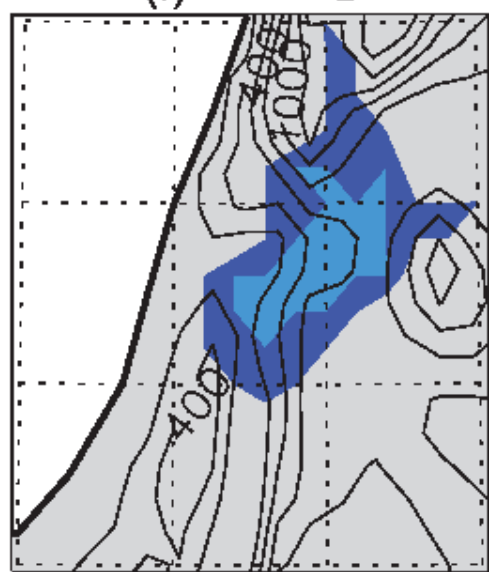

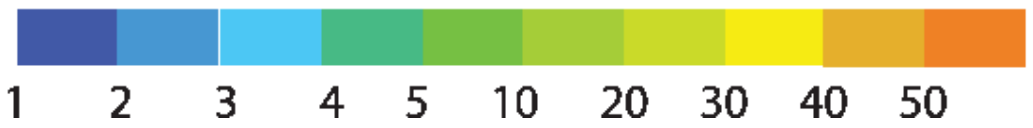

FIG. 15. As in Fig. 3, but for ISL $\left(31^{\circ}-34^{\circ} \mathrm{N}, 34^{\circ}-37^{\circ} \mathrm{E}\right)$ : (a),(b) DJF; (c),(d) MAM; and (e),(f) SON.

Intraseasonal Oscillation, described by Sanchez-Gomez et al. (2008). This oscillation consists of a sequence of positive and negative geopotential anomalies that propagate eastward over Europe. Phase 8, which shows a lowhigh pressure dipole with centers on the west of the British Islands and over Russia, respectively, represents the phase for which the probability of extreme precipitation events occurrence in this region is the largest (Sanchez-Gomez et al. 2008). As for the low-level conditions, our results are similar to those obtained from a clustering classification based on episodes of significant rainfall episodes (Joly et al. 2007): winds at $925 \mathrm{hPa}$ for significant rainfall in southern France are mostly southeasterlies and of the order of $10-12 \mathrm{~m} \mathrm{~s}^{-1}$ near the coast.
Although part of the rainfall variability over Turkey may be explained by large-scale circulation patterns such as the North Atlantic Oscillation and the Scandinavian pattern (Xoplaki et al. 2004; Türkeş and Erlat 2005), like for the western European sector, intense precipitating events in other regions of the Mediterranean are unlikely to project into one specific large circulation mode. This is also true for the southeastern Mediterranean. For the southern Levant, a well-defined train of $\mathrm{A} 8$ and $\mathrm{A} 88^{\prime}$ is evident and it is noteworthy that the trough over western Europe present in MAM and SON is of amplitude comparable to those found in the extreme DC composites for the Alpine Southside and southern France both in the A8 and A8' fields. 
$n=56$

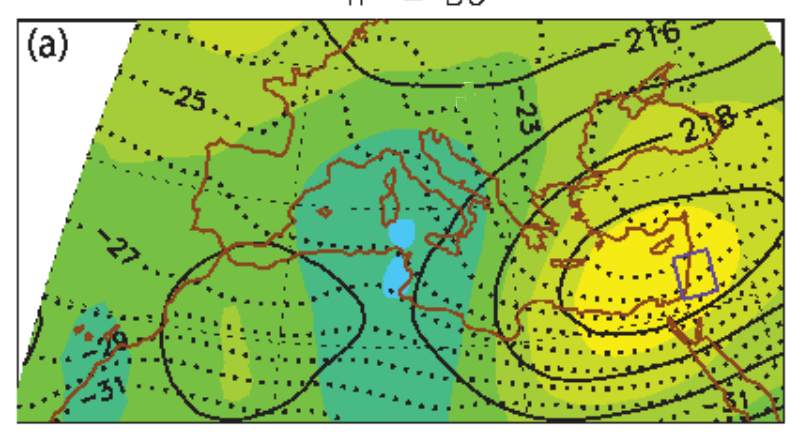

$n=45$

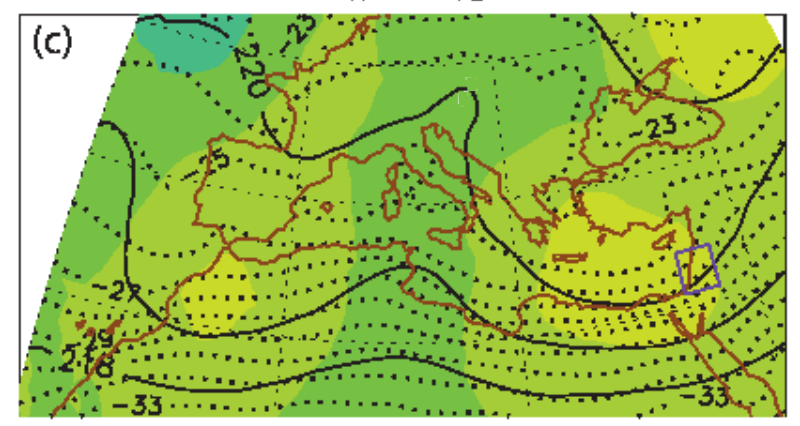

$n=17$

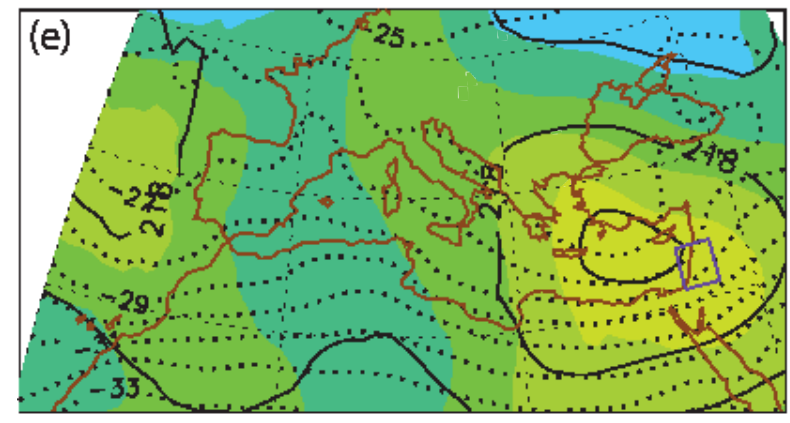

$n=4$

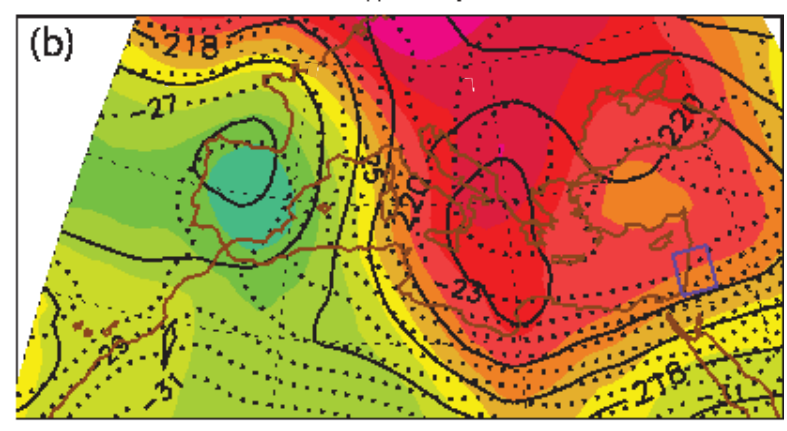

$n=4$

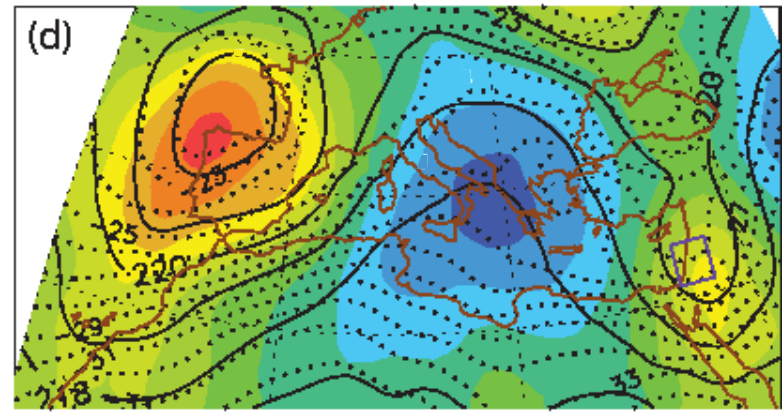

$n=2$

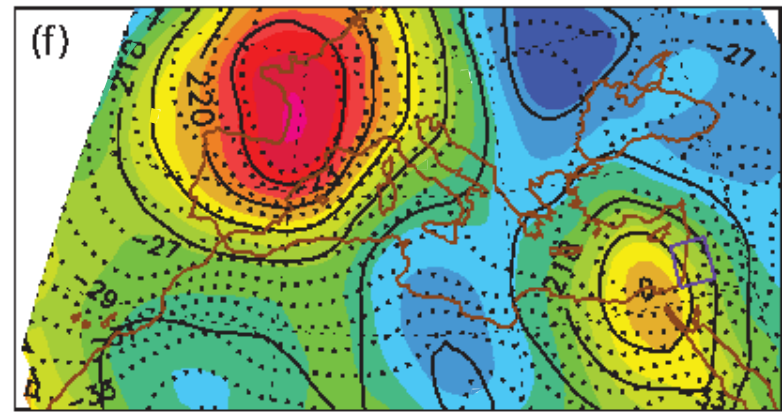

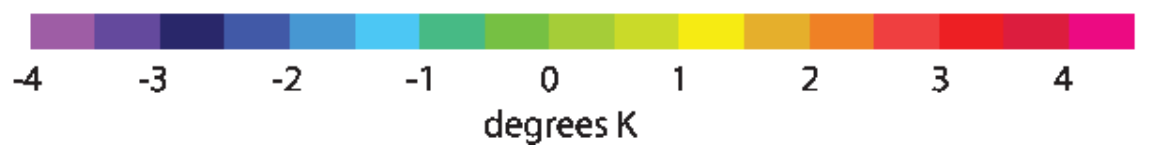

FIG. 16. As in Fig. 4, but for ISL: (a),(b) DJF; (c),(d) MAM; and (e),(f) SON.

A system presenting these values of $\mathrm{A} 8^{\prime}$ ( $3 \mathrm{~K}$ or more) has a chance of 1 to 2 out 5 in spring, and 1 out of 2 or 3 in autumn to have deep convective activity in its vicinity in the northwestern Mediterranean (Funatsu et al. 2008).

For most seasons in western Europe and Turkey in DJF, $\mathrm{SST}^{\prime}$ is up to $1 \mathrm{~K}$ warmer for extreme DC cases. Composite winds at $850 \mathrm{hPa}$ are of $\sim 10 \mathrm{~m} \mathrm{~s}^{-1}$ mostly from the southern quadrant, which causes moisture-laden air to impinge on the topographical barriers encircling these regions. For Turkey, the strong low-level southerly flow is associated to a well-marked low-level cyclonic circulation over the Aegean Sea. The southern Mediterranean cases (i.e., Tunisia and ISL) are both distinct from the northern Mediterranean cases and from each other. In the case of extreme DC in Tunisia, composites for SON and DJF show that SST' is up to $1 \mathrm{~K}$ warmer than in NCP cases, but our results show that the wind flow does not sweep over a considerable area over the sea, suggesting that low-level fluxes have secondary importance for the triggering and/or maintenance of deep convection. In ISL, SST' is warmer for extreme DC in DJF, but colder 
(a)

$$
\mathbf{n}=34
$$

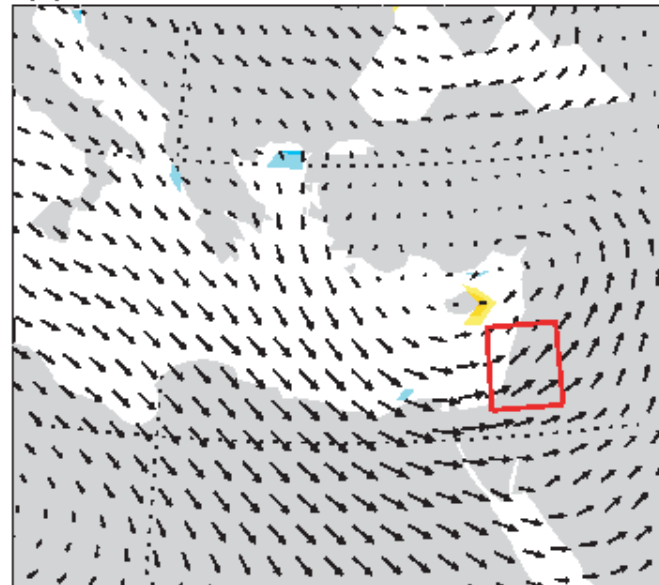

(c)

$$
\mathrm{n}=36
$$

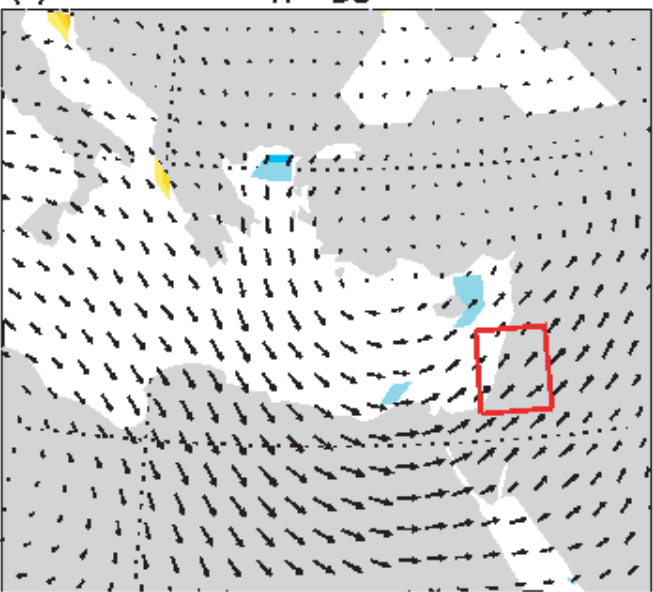

(e)

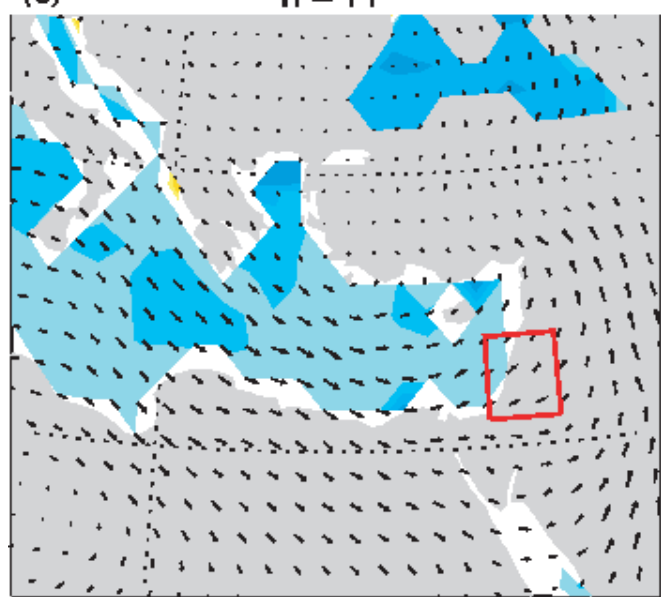

(b) $\quad \mathrm{n}=4$
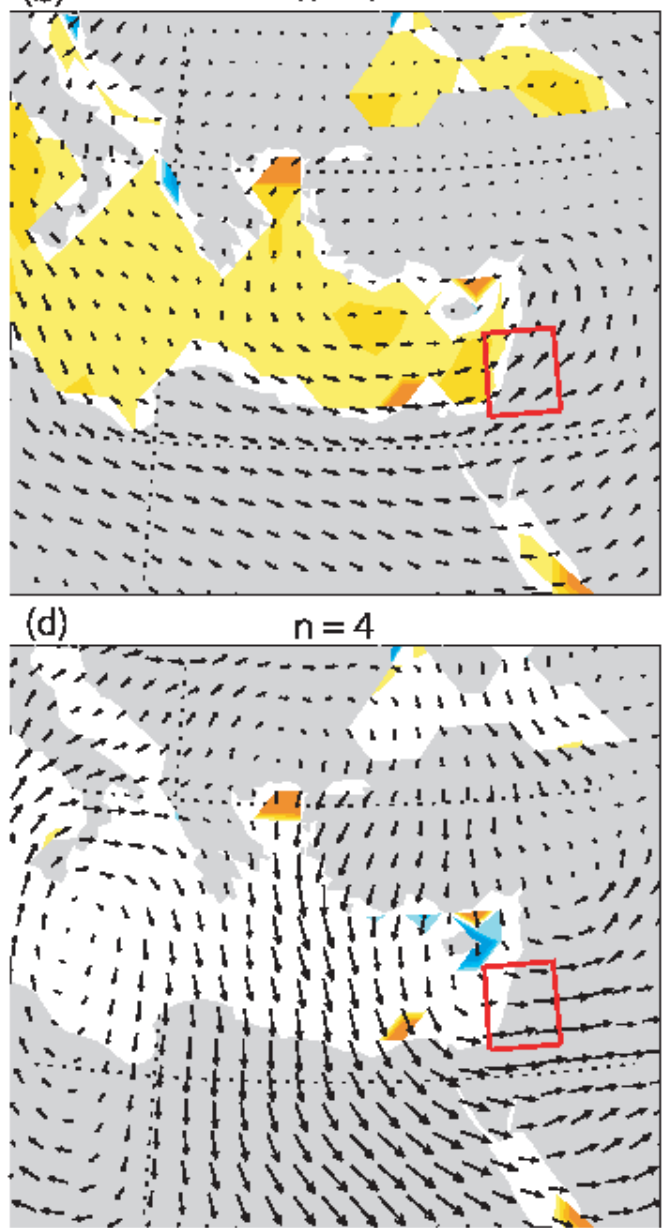

(f)

$$
\mathrm{n}=2
$$

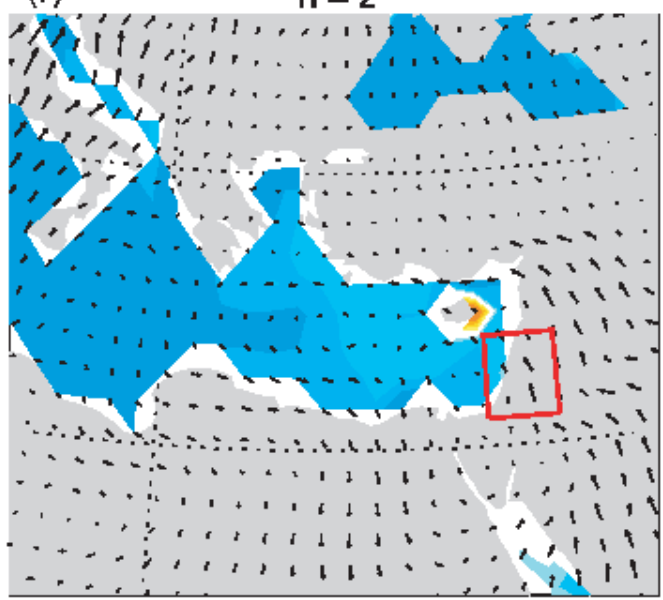

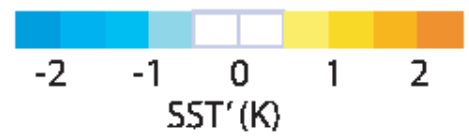

FIG. 17. As in Fig. 5, but for ISL: (a),(b) DJF; (c),(d) MAM; and (e),(f) SON. 
in SON, than for NCP cases; the influence of low-level fluxes is not apparent in these composites.

This study has several important aspects that improve our knowledge on the climatological picture of extreme precipitating events in the Mediterranean region. A correct representation of SST in the northern Mediterranean is important (up to 2-K difference between SST' of extreme DC cases and NCP). Not only the depth, but the exact location of the vertical penetration is crucial: although A7m5 BT value was only slightly different for both NCP and extreme DC events for example for Turkey, the NCP composites presented a more localized downward penetration, extending more to the south and being in the immediate upstream vicinity of the affected regions. Another point that is interesting are the patterns found in summer: during summer, convective events are mostly of localized nature, and are related to the internal variability of the regional system and less forced by disturbances coming from the midlatitudes (e.g., Martius et al. 2008). Here we show that the composite $A 8$ for the extreme DC events in JJA also presents a more pronounced trough to the west of the affected area as well as a wavelike pattern in the $\mathrm{A} 8^{\prime}$ fields. This implies that although the external forcing of the Mediterranean climate is smaller in summer, it may be an important component to the occurrence of extreme precipitation.

The upper-level pattern found in the $\mathrm{A} 8^{\prime}$ composites is part of a wave train that propagates eastward, and emulates the European-Mediterranean Intraseasonal Oscillation. Our results suggest that this oscillation impacts the entire Mediterranean basin. Two recent studies on Alpine Southside and Israel precipitation (Martius et al. 2008; Feldstein and Dayan 2008, respectively) showed that wave packets associated with heavy rainfall can be traced back on about one week to the Pacific during wintertime. As other regions in the world (e.g., Langland et al. 2002), a better representation of the planetary wave train would improve the medium-range forecast of Mediterranean heavy rainfall episodes. This stands also for the short term as small errors in the upperlevel conditions can affect the right location of rain forecasted at the mesoscale (Argence et al. 2009). The present study supports the need to collect data in areas upstream the Mediterranean, within the future Hydrological Cycle in the Mediterranean Experiment (HyMeX) field campaign (more information is available online at http://www.cnrm.meteo.fr/hymex/).

Acknowledgments. This study was sponsored by the French Ministry of Research through the Project ANRVMC2007 "Forecast and Projection in Climate Scenario of Mediterranean Intense Events: Uncertainties and Propagation on Environment" (MedUP). AMSU data was obtained through the French Mixed Service Unit ICARE. ECAD and GPCP data were obtained through the Web sites http://eca.knmi.nl and http://precip.gsfc. nasa.gov/, respectively. The authors thank two anonymous reviewers for their valuable comments, which improved the clarity of the text.

\section{REFERENCES}

Adler, R. F., and Coauthors, 2003: The version-2 Global Precipitation Climatology Project (GPCP) monthly precipitation analysis (1979-present). J. Hydrometeor., 4, 1147-1167.

Alpert, P., B. U. Neeman, and Y. Shay-El, 1990: Climatological analysis of Mediterranean cyclones using ECMWF data. Tellus, 42A, 65-77.

— M. Tzidulko, and D. Izigsohn, 1999: A shallow short-lived meso-beta cyclone over the gulf of Antalya, eastern Mediterranean. Tellus, 51A, 249-262.

— ranean extreme daily rainfall in spite of decrease in total values. Geophys. Res. Lett., 29, 1536, doi:10.1029/2001GL013554.

Argence, S., D. Lambert, E. Richard, J.-P. Chaboureau, and N. Söhne, 2008: Impact of initial condition uncertainties on the predictability of heavy rainfall in the Mediterranean: A case study. Quart. J. Roy. Meteor. Soc., 134, 1775-1788.

,,,,---- P. Arbogast, and K. Maynard, 2009: Improving the numerical prediction of a cyclone in the Mediterranean by local potential vorticity modifications. Quart. J. Roy. Meteor. Soc., 135, 865-879.

Barnston, A. G., and R. E. Livezey, 1987: Classification, seasonality, and persistence of low-frequency atmospheric circulation patterns. Mon. Wea. Rev., 115, 1083-1126.

Buehler, S. A., and V. O. John, 2005: A simple method to relate microwave radiances to upper tropospheric humidity. J. Geophys. Res., 110, D02110, doi:10.1029/2004JD005111.

—, M. Kuvatov, and V. O. John, 2005: Scan asymmetries in AMSU-B data. Geophys. Res. Lett., 32, L248110, doi:10.1029/ 2005 GL024747.

Chaboureau, J.-P., and C. Claud, 2006: Satellite-based climatology of Mediterranean cloud systems and their association with large-scale circulation. J. Geophys. Res., 111, D01102, doi:10.1029/2005JD006460.

Christian, H. J., and Coauthors, 2003: Global frequency and distribution of lighting as observed from space by the Optical Transient Detector. J. Geophys. Res., 108, D14005, doi:10.1029/ 2003JD002347.

Deeter, M. N., and J. Vivekanandan, 2005: AMSU-B observations of mixed-phase clouds over land. J. Appl. Meteor., 44, 72-85.

Delrieu, G., and Coauthors, 2005: The catastrophic flash-flood event of 8-9 September 2002 in the Gard Region, France: A first case study for the Cévennes-Vivarais Mediterranean Hydrometeorological Observatory. J. Hydrometeor., 6, 34-52.

Ducrocq, V., O. Nuissier, D. Ricard, C. Lebeaupin, and T. Thouvenin, 2008: A numerical study of three catastrophic precipitating events over southern France. Part II: Mesoscale triggering and stationarity factors. Quart. J. Roy. Meteor. Soc., 134, 131-145.

Fehlmann, R., C. Quadri, and H. C. Davies, 2000: An Alpine rainstorm: Sensitivity to the mesocale upper-level structure. Wea. Forecasting, 15, 4-28.

Feldstein, S. B., and U. Dayan, 2008: Circumglobal teleconnections and wave packets associated with Israeli winter precipitation. Quart. J. Roy. Meteor. Soc., 134, 455-467. 
Fourrié, N., C. Claud, and A. Chédin, 2003: Depiction of upperlevel precursors of the December 1999 storms from TOVS observations. Wea. Forecasting, 18, 417-430.

Frei, C., and C. Schär, 1998: A precipitation climatology of the Alps from high-resolution raingauge observations. Int. J. Climatol., 18, 873-900.

— H. C. Davies, J. Gurtz, and C. Schär, 2001: Climate dynamics and exteme precipitation and flood events in Central Europe. Integr. Assess., 1, 281-299.

— , J. H. Christensen, M. Déqué, D. Jacob, R. G. Jones, and P. L. Vidale, 2003: Daily precipitation statistics in regional climate models: Evaluation and intercomparison for the European Alps. J. Geophys. Res., 108, 4124, doi:10.1029/2002JD002287.

Funatsu, B. M., C. Claud, and J.-P. Chaboureau, 2007a: Two case studies of severe storms in the Mediterranean using AMSU. Adv. Geosci., 12, 19-26.

,-- , and,$- 2007 \mathrm{~b}$ : Potential of Advanced Microwave Sounding Unit to identify precipitating systems and associated upper-level features in the Mediterranean region: Case studies. J. Geophys. Res., 112, D17113, doi:10.1029/2006JD008297.

,$- \ldots$, and - 2008: A 6-year AMSU-based climatology of upper-level troughs and associated precipitation distribution in the Mediterranean region. J. Geophys. Res., 113, D15120, doi:10.1029/2008JD009918.

Giorgi, F., 2006: Climate change hot-spots. Geophys. Res. Lett., 33, L08707, doi:10.1029/2006GL025735.

Greenwald, T. J., and S. A. Christopher, 2002: Effect of cold clouds on satellite measurements near $183 \mathrm{GHz}$. J. Geophys. Res., 107, 4170, doi:10.1029/2000JD000258.

Hoinka, K. P., C. Schwierz, and O. Martius, 2006: Synoptic-scale weather patterns during Alpine heavy rain events. Quart. J. Roy. Meteor. Soc., 132, 2853-2860.

Holt, M. A., P. J. Hardaker, and G. P. McLelland, 2001: A lightning climatology for Europe and the UK, 1990-99. Weather, 56, 290-296.

Hong, G., G. Heygster, J. Miao, and K. Klaus, 2005: Detection of tropical deep convective clouds from AMSU-B vapour channels measurements. J. Geophys. Res., 110, D05205, doi:10.1029/2004JD004949.

Hulme, M., E. M. Barrow, N. W. Arnell, P. A. Harrison, T. C. Johns, and T. E. Downing, 1999: Relative impacts of human-induced climate change and natural variability. Nature, 397, 688-691.

Jacobeit, J., 1987: Vairations of trough position and precipitation patterns in the Mediterranean Area. J. Climatol., 7, 453-476.

Jansà, A., A. Genovés, M. A. Picornell, J. Campins, R. Riosalido, and O. Carretero, 2001: Western Mediterranean cyclones and heavy rain. Part 2: Statistical approach. Meteor. Appl., 8, 43-56.

Jasper, K., and P. Kaufmann, 2003: Coupled runoff simulations as validation tools for atmospheric models at the regional scale. Quart. J. Roy. Meteor. Soc., 129, 673-692.

Joly, B., O. Nuissier, V. Ducrocq, and A. Joly, 2007: Mediterranean synoptic scale ingredients involved in heavy precipitations events triggering over southern France: A clustering approach. Proc. 29th Int. Conf. on Alpine Meteorology, Chambéry, France, Météo-France, 4-8.

Kahana, R., B. Ziv, Y. Enzel, and U. Dayan, 2002: Synoptic climatology of major floods in the Negev Desert, Israel. Int. J. Climatol., 22, 867-882.

Karaca, M., and S. Dobricic, 1997: Modeling of summertime meso$\beta$ scale cyclone in the Antalya Bay. Geophys. Res. Lett., 24, $151-154$.
Klein Tank, A. M. G., and Coauthors, 2002: Daily dataset of 20thcentury surface air temperature and precipitation series for the European Climate Assessment. Int. J. Climatol., 22, 14411453.

Kotroni, V., K. Lagouvardos, E. Defer, S. Dietrich, F. Porcù, C. M. Medaglia, and M. Demirtas, 2006: The Antalya 5 December 2002 storm: Observations and model analysis. J. Appl. Meteor. Climatol., 45, 576-590.

Krichak, S. O., M. Tsidulko, and P. Alpert, 2000: Monthly synoptic patterns associated with wet/dry conditions in the eastern Mediterranean. Theor. Appl. Climatol., 65, 215-229.

Kurupinar, M., 1995: Investigation of the topographical effects on the precipitation distribution over Turkey by satellite data. Geosci. Remote Sens., 1, 371-373.

Langland, R. H., M. A. Shapiro, and R. Gelaro, 2002: Initial condition sensitivity and error growth in forecasts of the 25 January 2000 East Coast snowstorm. Mon. Wea. Rev., 130, 957-974.

Lebeaupin, C., V. Ducrocq, and H. Giordani, 2006: Sensitivity of torrential rain events to the sea surface temperature based on high-resolution numerical forecasts. J. Geophys. Res., 111, D12110, doi:10.1029/2005JD006541.

Martius, O., E. Zenklusen, C. Schwierz, and H. C. Davies, 2006: Episodes of Alpine heavy precipitation with an overlying elongated stratospheric intrusion: A climatology. Int. J. Climatol., 26, 1149-1164, doi:10.1002/joc.1295.

— C. Schwierz, and H. C. Davies, 2008: Far-upstream precursors of heavy precipitation events on the Alpine south-side. Quart J. Roy. Meteor. Soc., 134, 417-428.

Massacand, A. C., H. Wernli, and H. C. Davies, 1998: Heavy precipitation on the alpine southside: An upper-level precursor. Geophys. Res. Lett., 25, 1435-1438.

Nuissier, O., V. Ducrocq, D. Ricard, C. Lebeaupin, and S. Anquetin, 2008: A numerical study of three catastrophic precipitating events over southern France. Part I: Numerical framework and synoptic ingredients. Quart. J. Roy. Meteor. Soc., 134, 111-130.

Porcù, F., C. Caracciolo, and F. Prodi, 2003: Cloud systems leading to flood events in Europe: Overview and classification. Meteor. Appl., 10, 217-227.

Riosalido, R., 1990: Characterization of mesoscale convective systems by satellite pictures during PREVIMET MEDITERRANEO-89 (in Spanish). Segundo Simposio Nacional de Predicción, Madrid, Spain, Instituto Nacional de Meteorología, 135-148.

Rondanelli, R., and R. S. Lindzen, 2008: Observed variations in convective precipitation fraction and stratiform area with sea surface temperature. J. Geophys. Res., 113, D16119, doi:10.1029/2008JD010064.

Saaroni, H., and B. Ziv, 2000: Summer rain episodes in a Mediterranean climate, the case of Israel: Climatological-dynamical analysis. Int. J. Climatol., 20, 191-209.

Sanchez-Gomez, E., and L. Terray, 2005: Large-scale atmospheric dynamics and local intense precipitation episodes. Geophys. Res. Lett., 32, L24711, doi:10.1029/2005GL023990.

— - _ and B. Joly, 2008: Intra-seasonal atmospheric variability and extreme precipitation events in the EuropeanMediterranean region. Geophys. Res. Lett., 35, L15708, doi:10.1029/2008GL034515.

Sénési, S. P., P. Bougeault, J.-L. Chèze, P. Cosentino, and R. Thepenier, 1996: The Vaison-la-Romaine flash-flood: Mesoscale analysis and predictability issues. Wea. Forecasting, 11, $417-442$. 
Sharon, D., and H. Kutiel, 1986: The distribution of rainfall intensity in Israel, its regional and seasonal variations and its climatological evaluation. Int. J. Climatol., 6, 277-291.

Trigo, I. F., T. D. Davies, and G. R. Bigg, 1999: Objective climatology of cyclones in the Mediterranean region. J. Climate, 12, 1685-1696.

— , G. R. Bigg, and T. D. Davies, 2002: Climatology of cyclogenesis mechanisms in the Mediterranean. Mon. Wea. Rev., 130, 549-569.

Tripoli, G. J., C. M. Medaglia, S. Deitrich, A. Mugnai, G. Panegrossi, S. Pinori, and E. A. Smith, 2005: The 9-10 November 2001 Algerian flood: A numerical study. Bull. Amer. Meteor. Soc., 86, 1229-1235.

Tsvieli, Y., and A. Zangvil, 2007: Synoptic climatological analysis of Red Sea Trough and non-Red Sea Trough rain situations over Israel. Adv. Geosci., 12, 137-143.

Türkeş, M., and E. Erlat, 2005: Climatological responses of winter precipitation in Turkey to variability of the North Atlantic Oscillation during the period 1930-2001. Theor. Appl. Climatol., 81, 45-69.

Uppala, S., and Coauthors, 2005: The ERA-40 Re-Analysis. Quart. J. Roy. Meteor. Soc., 131, 2961-3012.

Vautard, R., 1990: Multiple weather regimes over the North Atlantic: Analysis of precursors and successors. Mon. Wea. Rev., 118, 2056-2081.
Walser, A., and C. Schär, 2004: Convection-resolving precipitation forecasting and its predictability in Alpine river catchments. J. Hydrol., 288, 57-73.

Weng, F., L. Zhao, R. R. Ferraro, G. Poe, X. Li, and N. C. Grody, 2003: Advanced Microwave Sounding Unit cloud and precipitation algorithms. Radio Sci., 38, 8068, doi:10.1029/ 2002RS002679.

Wentz, F. J., C. Gentemann, D. Smith, and D. Chelton, 2000: Satellite measurements of sea surface temperature through clouds. Science, 288 (5467), 847-850, doi:10.1126/ science.288.5467.847.

Xoplaki, E., J. F. González-Rouco, J. Luterbacher, and H. Wanner, 2004: Wet season Mediterranean precipitation variability: Influence of large-scale dynamics and trends. Climate Dyn., 23, 63-78, doi:10.1007/s00382-004-0422-0.

Zangvil, A., S. Karas, and A. Sasson, 2003: Connection between Eastern Mediterranean seasonal mean $500 \mathrm{hPa}$ height and sealevel pressure patterns and the spatial distribution over Israel. Int. J. Climatol., 23, 1567-1576.

Ziv, B., H. Saaroni, and P. Alpert, 2004: The factors governing the summer regime of the eastern Mediterranean. Int. J. Climatol., 24, 1859-1871.

, U. Dayan, Y. Kushnir, C. Roth, and Y. Enzel, 2006: Regional and global atmospheric patterns governing rainfall in the southern Levant. Int. J. Climatol., 26, 55-73. 